\title{
Sequential enrichment at the nuclear periphery of H2A.Zac and H3K9me2 accompanies pluripotency loss in human embryonic stem cells
}

\author{
Georgia Rose Kafer $^{1,2}$, Regina Rillo-Bohn ${ }^{1,3}$, and Peter M. Carlton ${ }^{1,4, \varpi}$ \\ ${ }^{1}$ Institute for Integrated Cell-Material Sciences (iCeMS), Kyoto University \\ ${ }^{2}$ current address: Genome Integrity Unit, The Children's Medical Research Institute, Westmead, NSW Australia \\ ${ }^{3}$ current address: Department of Microbiology and Molecular Genetics, University of California, Davis \\ ${ }^{4}$ current address: Graduate School of Biostudies and Radiation Biology Center, Kyoto University
}

\begin{abstract}
During the transition from pluripotency to a lineage-committed state, chromatin undergoes large-scale changes in structure to effect the required changes to the transcriptional program. This involves covalent modification of histone tails, replacement of histone variants, and alteration in the subnuclear position of genes, including associations with the nuclear periphery. Here, using high-resolution microscopy and quantitative image analysis, we surveyed a panel of histone variants and covalent modifications for changes in nuclear periphery association during differentiation of human embryonic stem cells to a trophoblast-like lineage. This differentiation process is rapid and homogeneous, facilitating the use of a relatively fine timecourse $(12 \mathrm{~h}, 24 \mathrm{~h}$, and $48 \mathrm{~h}$ post-initiation) to enable detection of transient changes. With this scheme, we detected two modifications with significant changes in enrichment at the nuclear periphery: acetylation of histone variant H2A.Z, and dimethylation of histone $\mathrm{H3}$ at lysine 9. We show that these chromatin marks increase specifically at the nuclear periphery in a sequential, complementary manner, with a H2A.Z acetylation preceding H3K9 dimethylation. The increase of $\mathrm{H} 3 \mathrm{~K} 9$ dimethylation occurred coincidentally with but independently of accumulation of Lamin A, since Lamin $\mathrm{A}^{-/-} \mathrm{hES}$ cells showed no changes in the localization pattern of $\mathrm{H3K9}$ dimethylation. Inhibition of histone deacetylases led to persistent and increased $\mathrm{H} 2 \mathrm{~A} . \mathrm{Z}$ acetylation at the periphery, and failure to differentiate. Our results show that a concerted dynamic change in the nature of peripheral chromatin is required for differentiation into the trophoblast state.
\end{abstract}

Chromatin modification | H2A.Z | H3K9me2 | Trophoblast

Correspondence: carlton.petermark.3v@kyoto-u.ac.jp

\section{Introduction}

Pluripotent cell differentiation is accompanied by extensive changes in the expression of pluripotency and lineagespecific genes. Gene expression changes are controlled in turn by several mechanisms which include differential activity of transcription factors, covalent modifications of DNA or chromatin, and movement of gene loci into silent or active nuclear compartments (1). While our understanding of the transcriptional networks required for the stem cell state and commitment to a variety of lineages is well developed, (2) our knowledge regarding the role of chromatin changes and nuclear subcompartments in differentiation is not as comprehensive. Some clues have emerged from work on mouse embryonic stem cells (mESCs), where upon differentiation, genes which are required in the newly established cell lineages shift from being late replicating to earlier replicating $(3,4)$. This shift in replication timing also correlates with dissociation from the nuclear periphery during differentiation, since DNA at the periphery tends to be replicated later than active, euchromatic regions $(1,5)$. The nuclear periphery is in general a gene-repressive compartment (6); however, no universal causal relationship between gene position and transcriptional state has been defined. Movement of genes to and from the nuclear periphery is influenced by the covalent modification of histone proteins (7); especially, association of heterochromatin with the nuclear periphery is strongly correlated with dimethylation of histone $\mathrm{H} 3$ at lysine 9 (8-11). H3K9me2-marked chromatin can undergo dynamic relocalization to and from the nuclear periphery in a lineage-specific manner during differentiation (12). The nuclear lamina, a meshwork at the nuclear periphery, is composed of Lamin A, its splice variant Lamin C, Lamin B, and their interacting proteins. Of these, Lamin A/C and the Lamin B Receptor (LBR), have been strongly implicated in anchoring heterochromatin to the nuclear periphery in multiple cell types (13). While Lamin A and its splice variant Lamin C make up the bulk of the nuclear lamina in differentiated cells, these are only expressed at low levels in pluripotent cells; consequently, the lamina in pluripotent cells is composed largely of only Lamin B. Whether the low level of Lamin A present in undifferentiated human ES cells plays a role in transcriptional control is not clear.

Several reports have shown that the differentiation of stem cells is accompanied by significant changes in covalent DNA and histone protein modification which influence the activity of genes $(14,15)$. H3K9 di- or trimethylation is consistently associated with transcriptional repression, and targets lineage-associated genes during differentiation (16). Large H3K9me2 domains are present in both undifferentiated and differentiated cells (17), but these undergo dynamic changes at the local level during differentiation. H2A.Z is a histone variant whose many roles are modulated by post-translational modifications, and is exchanged for canonical $\mathrm{H} 2 \mathrm{~A}$ by the Tip60 complex. While H2A.Z itself has been found in both repressive and activating contexts (18), its acetylated form has exclusively been found correlated with gene activation (19-21). Global and predictable changes in chromatin modifications between different nuclear compartments in differentiated and undifferentiated stem cells have also been reported (22). Despite these studies, we still know little about the kinetics of establishing chromatin environments during lineage commitment. Especially, the relationship between chromatin modifications and different nuclear compartments in cells at intermediate states between pluripotency and terminal differentiation is not understood well. Further, while 
information from ensembles of cells is able to reveal information about chromatin changes at high genomic resolution, it fails to show changes in 3D nuclear architecture of individual cells.

Trophoblast cells are the first cells to terminally differentiate in vivo, and eventually make up the extraembryonic placental tissue. Trophoblast-like (TBL) cells can be effectively and homogeneously differentiated from primed hESCs through treatment with BMP4 and simultaneous inhibition of FGF and Activin / Nodal signaling $(23,24)$. Compared to other commonly employed differentiation pathways to generate neural progenitor or mesoderm lineages, TBL differentiation generates cells that are immediately terminally committed, finish differentiation in less than 1 week, and exhibit characteristic chromatin states, including significant hypomethylation and distinct chromatin organization in a highly homogeneous manner (25-27). The fast, unidirectional, homogeneous nature of TBL cell differentiation provides a tool to study cellular events that happen immediately upon differentiation.

In this study we have analysed individual human embryonic stem cells (hESCs) to assay the localization of modified histones with respect to the nuclear periphery during early phases of pluripotency loss and into the beginning stages of terminal lineage commitment to trophoblast-like (TBL) cells. We visualized histone modifications with immunofluorescence using high resolution microscopy, and quantitatively analyzed the three-dimensional nuclear distribution of histone modifications relative to the nuclear periphery. To this end, we developed an automated program which recognizes and crops individual nuclei in three dimensions, and executes shell analysis to quantitatively examine distancedependent distribution patterns of histone modifications relative to the nuclear periphery in hundreds of cells. Our shell analysis program is applicable to many different types of cells and signals whose distribution relative to nuclear periphery are to be determined. We surveyed dynamic changes of modified chromatin (H3K4me3, H3K9me2, H3K9me3, H3K27ac, H3K27me3, H3K36me3) and one histone variant (H2A.Z) and its acetylated form (H2A.Zac) in hESCs from both primed and "naïve" pluripotent states $(28,29)$ in addition to hESCs which are differentiating to the trophoblast lineage. We show that two histone modifications, the dimethylation of histone 3 at lysine 9 (H3K9me2) and Nterminal acetylation of the histone variant H2A.Z (H2A.Zac) show changes in their distribution at the nuclear periphery as hESCs transition from naïve to primed and differentiated states. Particularly, we have captured transient association of H2A.Zac to the nuclear periphery within $12 \mathrm{~h}$ upon loss of pluripotency, and found that this coincides with the transient loss of $\mathrm{H} 3 \mathrm{~K} 9 \mathrm{me} 2$ from the nuclear periphery during the differentiation process. Our analysis uncovered that transient and dynamic nuclear periphery association of specific histone modifications may occur during intermediate stages of differentiation. Such transient changes could be missed by only analyzing cells after the completion of differentiation. Further, we show that HDAC activity is a key controlling factor in the establishment of chromatin environments at the nuclear periphery during differentiation.

\section{Results}

Characterization of fast, homogeneous differentiation from hES cells to the TBL lineage. We first characterized the extent to which our TBL induction scheme could produce homogeneous, rapid pluripotency loss and differentiation from hES to TBL cells. We subjected primed hESCs to a treatment inducing TBL differentiation, as previously described $(23,24)$ (Fig. 1A, see Methods) and observed changes in gross cellular morphology, as well as the development of characteristic chromatin morphology revealed by DAPI staining (Fig. 1B). This DAPI morphology is qualitatively similar to that seen in early human placental sections (27). Immunofluorescence indicated that TBL induction caused a drop in NANOG and OCT4 (POU4F1) levels within 24 hours (Fig. 1 C), and single-molecule RNA FISH confirmed that NANOG mRNA levels were downregulated at this time (Fig. 1 D). The mRNA for $C D X 2$, a gene essential for placental development (30), was detectable 48 hours post induction and was specifically detected in a subset of cells at 96 hours that displayed DNA morphology qualitatively similar to in vivo human cytotrophoblast (27) (Fig. 1 E). Immunofluorescence also demonstrated that the trophoblast specific marker Cytokeratin 7 was expressed in cells possessing the cytotrophoblast-like DNA morphology at 4 and 6 days post induction (Fig. S1A), as were other human trophoblast markers GCM1, SYNA and hCG (Fig. S1B). Lamin A, a nuclear envelope protein which is not abundantly expressed in pluripotent hESCs (31) and shows extremely sparse staining in undifferentiated hESCs, became clearly detectable at the nuclear periphery 48 hours after TBL induction (Fig.1F). Taken together, these results indicate our differentiation scheme is capable of rapid and homogeneous differentiation as measured by these cell fate markers.

\section{H2A.Zac and H3K9me2 undergo waves of relocation at the nuclear periphery as hESCs lose pluripotency and differentiate. We reasoned that if both subnuclear po- sition and covalent histone modifications were involved in modulating gene expression, then subnuclear changes in hi- stone modification should be cytologically visible across a differentiation time course. Using immunofluorescence, we examined the intensity and localization pattern of sev- eral histone modification marks associated with either ac- tive or inactive chromatin (H3K4me3, H3K9me2, H3K9me3, $\mathrm{H} 3 \mathrm{~K} 27 \mathrm{ac}, \mathrm{H} 3 \mathrm{~K} 27 \mathrm{me} 3, \mathrm{H} 3 \mathrm{~K} 36 \mathrm{me} 3$ ) as well as one histone variant (H2A.Z) and its acetylated form (H2A.Zac), in hESC and at 24 hours post TBL induction (Fig. 2). The subnu- clear distribution of H3K4me3, H3K36me3, H3K27me3 and H3K9me3 did not noticeably change following 24 hours of differentiation (Fig. 2 C, D, F and $\mathbf{H}$ ). The subnuclear dis- tribution of pan-H2A.Z and H3K27ac within the nucleus also remained similar throughout differentiation, although nuclear intensity qualitatively decreased in differentiating cells (Fig. 2 A, E).}


bioRxiv preprint doi: https://doi.org/10.1101/2020.02.15.951103; this version posted February 16, 2020. The copyright holder for this preprint (which was not certified by peer review) is the author/funder, who has granted bioRxiv a license to display the preprint in perpetuity. It is made available under aCC-BY-NC-ND 4.0 International license.
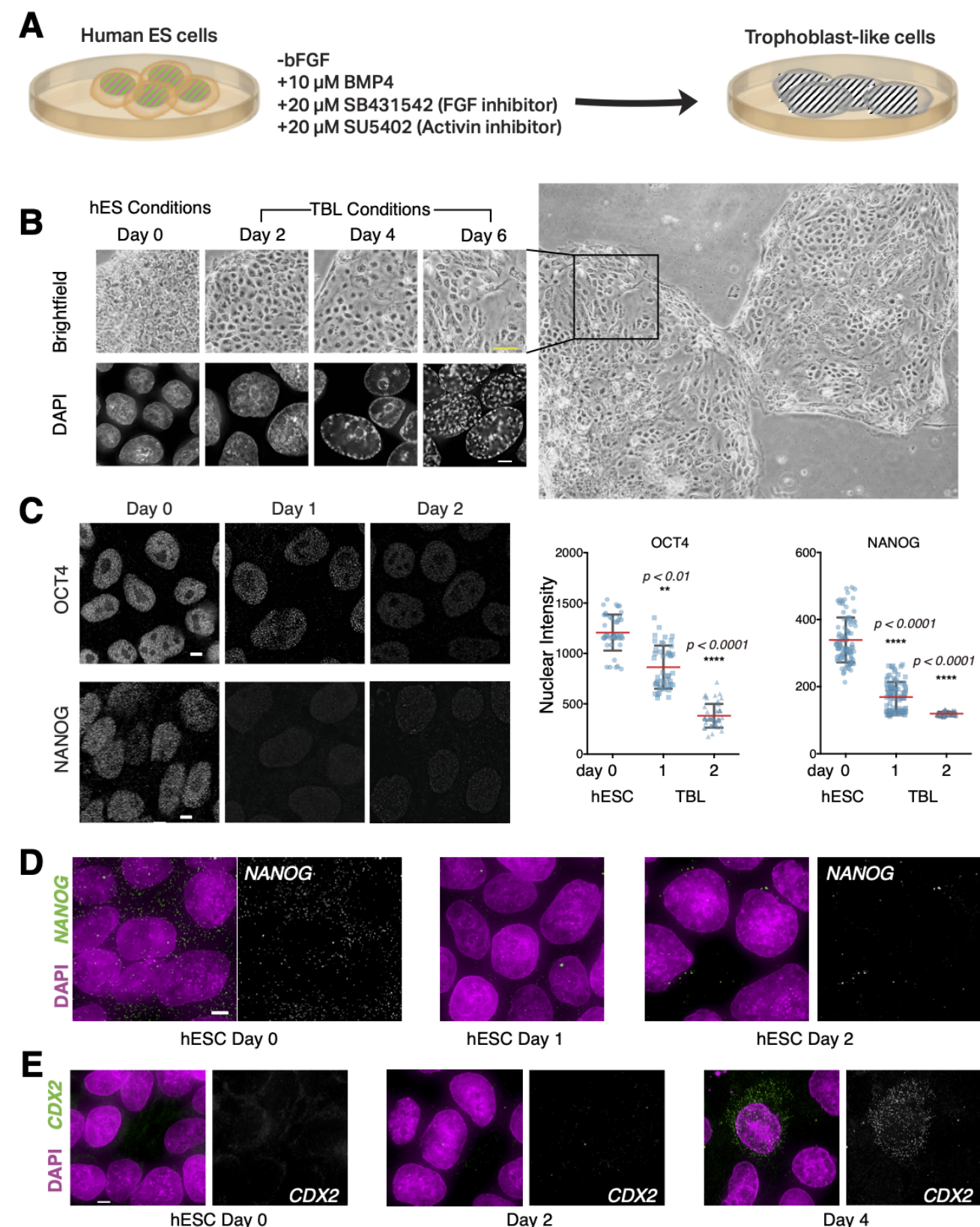

hESC Day 1

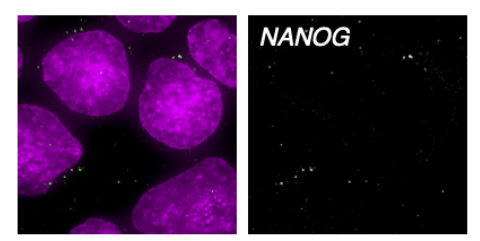

hESC Day 2
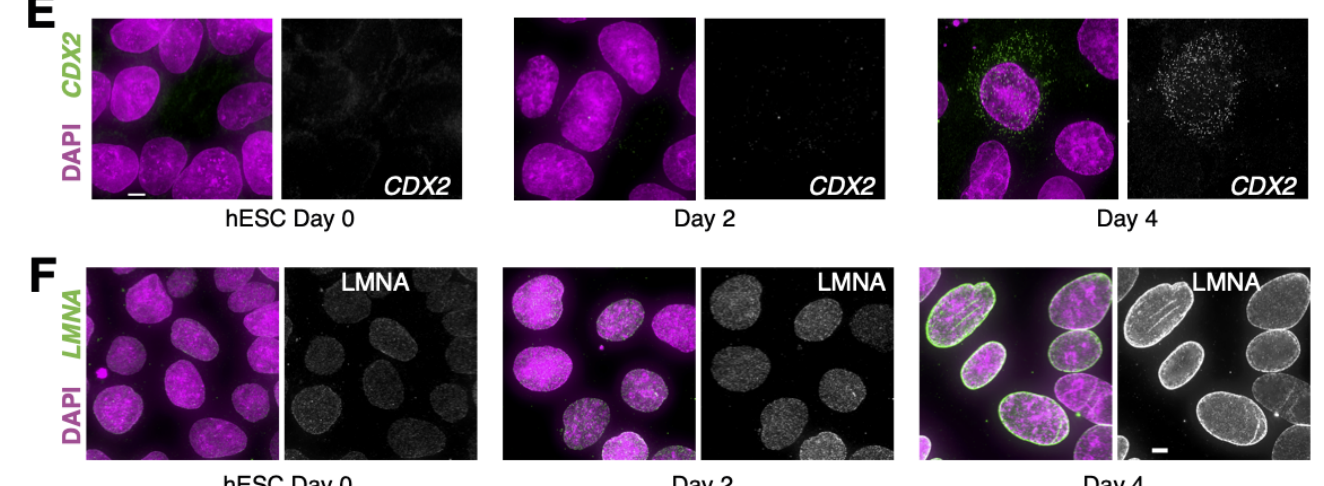

Day 2

Day 4

Fig. 1. Changes in morphology and gene expression of human embryonic stem cells during differentiation to a trophoblast-like state. A, schematic of the differentiation procedure. B, Changes in colony morphology, nuclear staining using DAPI, and pluripotency markers Oct4 and NANOG using immunofluorescence, during differentiation. For the brightfield image of Day 6 , the larger field of which it is a subset is shown adjacent. Scale bars: $30 \mu \mathrm{m}$ (top), $5 \mu \mathrm{m}$ (bottom). C, quantitation of intensity levels of Oct4 and NANOG from panel B; red lines show mean intensity values and bars extend to one standard deviation; significance levels for difference of means from day 0 are shown. D, single-molecule FISH against NANOG mRNA is shown in green; DAPI staining in magenta. E, single-molecule FISH against Cdx2 mRNA is shown in green; DAPI staining in magenta. $\mathbf{F}$, immunofluorescence against Lamin A is shown in green; DAPI staining in magenta. Scale bars, $5 \mu \mathrm{m}$.

In contrast, two of the tested histone modifications, H2A.Zac and $\mathrm{H} 3 \mathrm{~K} 9 \mathrm{me} 2$, showed marked changes in nuclear distribution as cells lost pluripotency. Under hESC conditions,
H2AZac was distributed evenly throughout the nucleus. After 24 hours of differentiation, H2AZac signal appeared enriched at the nuclear periphery and was reduced in the nucle- 


\section{Figure 2}
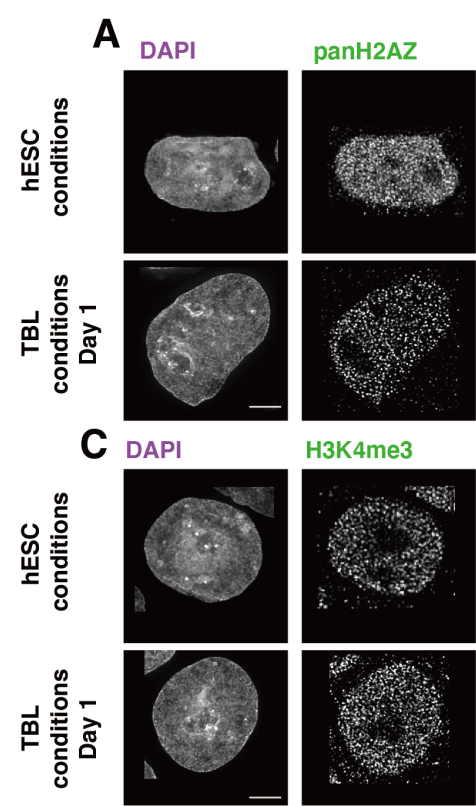

H3K4me3
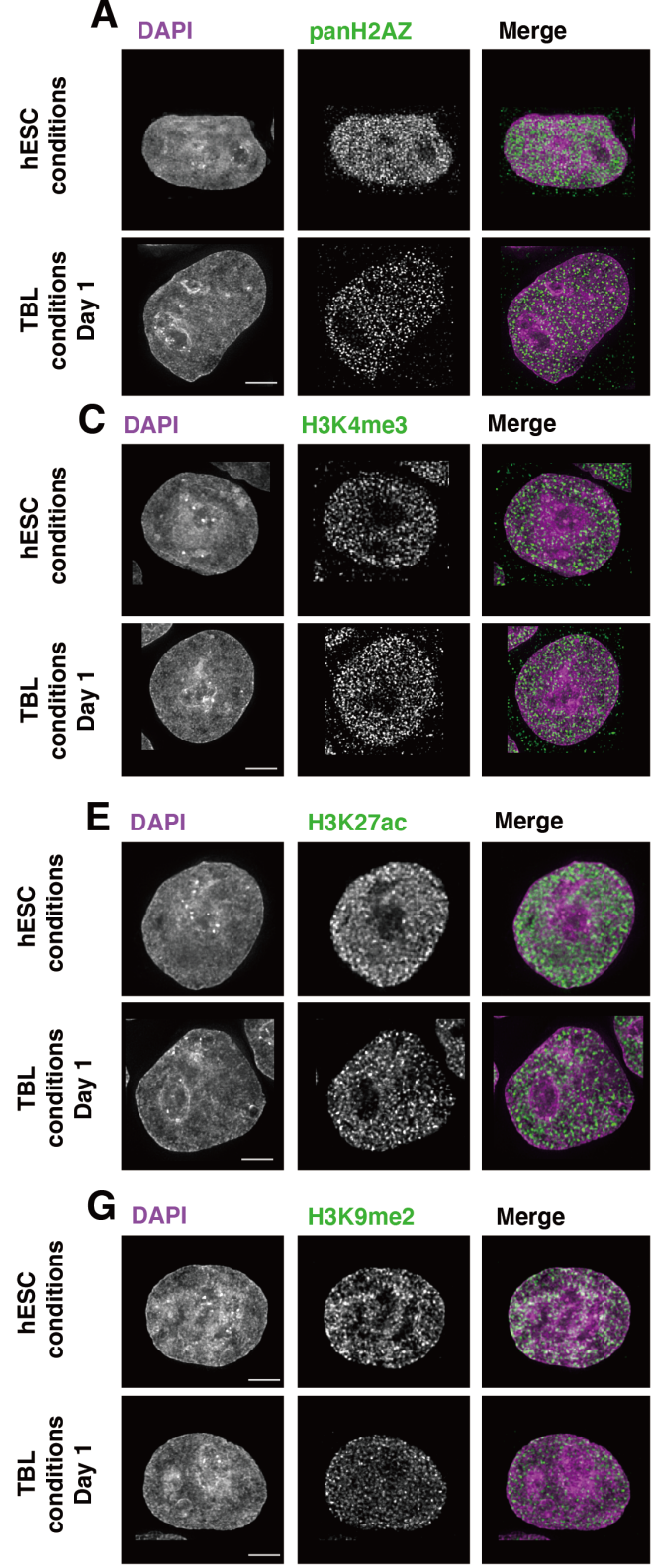

Merge

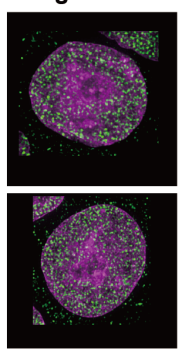

Merge
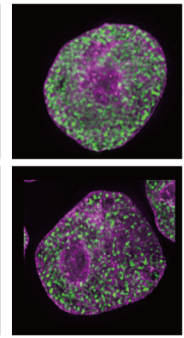

Merge
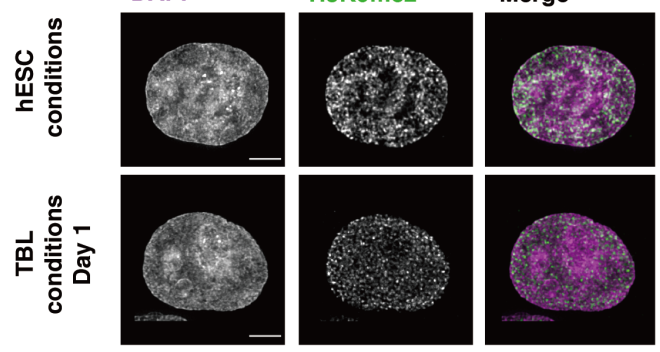

B

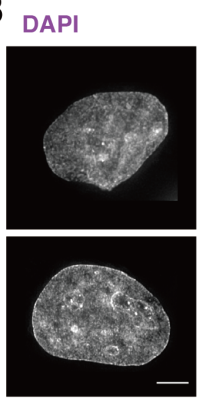

D DAPI

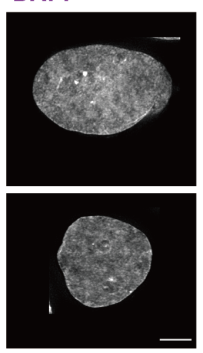

F DAPI
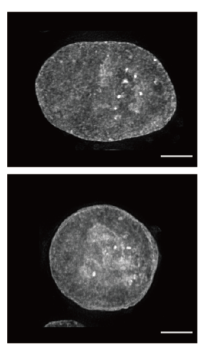

H DAPI
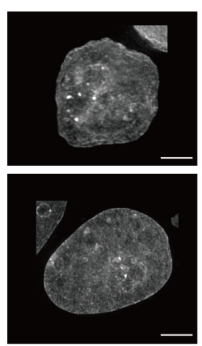

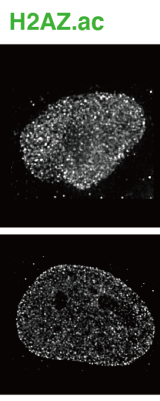

H3K36me3
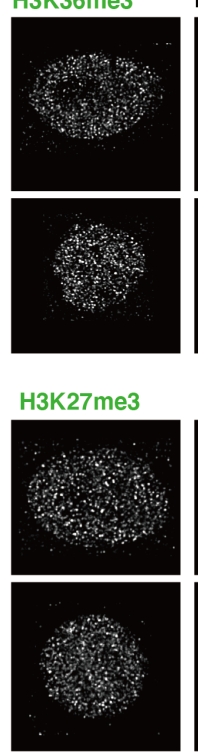

H3K9me3

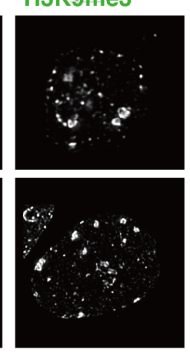

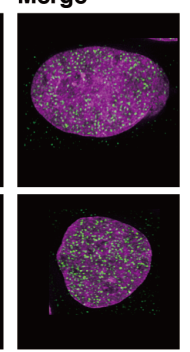

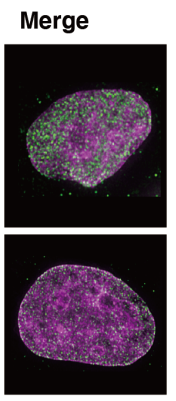

Merge

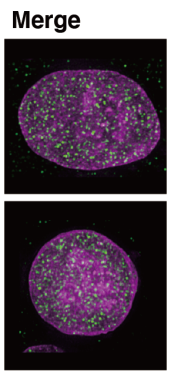

Merge

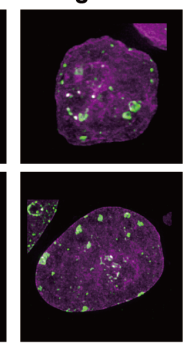

Fig. 2. Chromatin markers display dynamic changes during differentiation. Cells in either hES media (top) or $24 \mathrm{~h}$ after changing to TBL differentiation media (bottom) were stained with antibodies against the indicated chromatin markers. DAPI staining is shown in grayscale and magenta in the merged column; chromatin markers shown in grayscale and green in the merged column. Scale bars, $5 \mu \mathrm{m}$.

oplasm (Fig 2B). Interestingly, H3K9me2 signals appeared to change in a manner opposite to that of $\mathrm{H} 2 \mathrm{AZac}$ : undifferentiated hESCs displayed enriched $\mathrm{H} 3 \mathrm{~K} 9 \mathrm{me} 2$ at the nuclear periphery, which was lost 24 hours after differentiation (Fig 2G).

To fully characterise H2A.Zac and H3K9me2 dynamics across all hESC stages, we took samples at 12, 24, 48 and 96 hours after the commencement of differentiation. To determine whether the pattern of histone modifications in non-differentiated hESC is characteristic of the primed state and the naïve state ( a distinct, developmentally-earlier state of pluripotency in which cells are less prone to differentiate), we compared conventionally-cultured hESC (referred to hereafter as primed hESC) to naïve hESC. To quantitatively assess the apparent enrichment of signals at the nuclear periphery by immunofluorescence, we implemented a shell averaging program operating on three-dimensional images (Fig. 3A). The source images for the program are threedimensional fields of $\sim 15 \mu \mathrm{m}$ depth containing from $2-10$ cell nuclei. The DAPI channel is used to automatically segment 
each nucleus into its own new image, and is also used to define the nuclear periphery. The mid-section of the image is automatically detected, and fluorescence intensity is then averaged in each of a series of twenty concentric shells reaching from $0.5 \mu \mathrm{m}$ outside the nuclear periphery to $\sim 1.5 \mu \mathrm{m}$ inside, in five $\mathrm{Z}$ sections surrounding the midsection. The shells intentionally begin outside the true nuclear periphery to create a detectable peak in the nuclear signal. For each experiment, a montage of all segmented nuclei is automatically generated, which is used to visually exclude instances of failed segmentation (e.g., partial nuclei; or several nuclei being falsely detected as a single nucleus).

For each experiment, cells were fixed at different time points and kept at $4^{\circ}$; immunostaining of all samples was then conducted at the same time to minimize technical variability. Images were acquired with the same exposure time in each wavelength to facilitate direct comparisons, and at least 90 cells total were analyzed from two or three biological replicates in all cases. The reliability of this method was confirmed by a consistent $200 \mathrm{~nm}$ average peak distance measured between the peak of Lamin A/C immunostaining and the peak of DAPI staining in differentiated cells (Fig. S2). Using this method, we found that H2A.Zac was initially low and diffuse in naïve hESC, but in primed hESC, H2A.Zac was found more strongly throughout the nucleus and was occasionally enriched at the nuclear periphery (Fig. 3B). At 12 hours post TBL induction, most hESCs showed peripheral enrichment of H2AZac while internal levels declined. After 24 hours of differentiation cells still exhibited H2A.Zac enrichment at the nuclear periphery, but both peripheral and nucleoplasmic levels appeared reduced compared to cells at 12 hours. At 2 days post differentiation, most nuclei no longer displayed peripherally-enriched H2A.Zac, and by 96 hours H2A.Zac signal became very low throughout the whole nucleus. Quantitative analysis showed that total nuclear H2A.Zac signal was low in naïve hESC, high in primed hESCs and generally declined with differentiation (Fig. 3C). Peripheral shell analysis across the population demonstrated that there were some cells with peripheral H2A.Zac enrichment at all timepoints assayed, but at 12 and 24 hours post differentiation the majority of the population exhibited peripheral H2A.Zac.

To test whether peripheral enrichment was specific to the acetylated version of H2A.Z, we also characterised panH2A.Z dynamics. In both naïve and primed hESC panH2A.Z was seen as small nucleoplasmic foci that were present throughout the nucleus, though more intense in primed cells (Fig. S3). After 24 hours of TBL induction, pan-H2A.Z levels remained high in the nucleoplasm, but further differentiation was accompanied by a decrease back to naïve levels. While pan-H2A.Z detected by immunofluorescence also changed dynamically, it was not enriched at the nuclear periphery, indicating that the periphery is specifically enriched for acetylation of H2A.Z.

We next assayed H3K9me2 dynamics across the 4-day differentiation time course. We found that $\mathrm{H} 3 \mathrm{~K} 9 \mathrm{me} 2$ appeared at the nuclear periphery in a pattern strikingly opposite to
H2A.Zac. H3K9me2 was significantly peripheral in naïve cells, reaching peak intensity within $0.7 \mu \mathrm{m}$ from the thresholded nuclear periphery (Fig. 3D), the same shell as the peak of DAPI intensity due to peripheral heterochromatin. Peripheral enrichment was reduced in primed hESC relative to naïve hESC nuclei, and by 12 hours following the initiation of differentiation, both peripheral and internal H3K9me2 signal were significantly reduced (Fig. 3D). Nucleoplasmic $\mathrm{H} 3 \mathrm{~K} 9 \mathrm{me} 2$ signal returned at 24 hours post differentiation and from 48 hours, cells exhibited robust H3K9me2 signal at the nuclear periphery (Fig. 3D). Quantitative analysis showed that the total H3K9me2 signal appeared relatively consistent across differentiation (Fig. 3E). Population wide peripheral shell analysis revealed that primed hESC and cells at 12 and 24 hours of differentiation displayed reduced $\mathrm{H} 3 \mathrm{~K} 9 \mathrm{me} 2$ signal at the nuclear periphery relative to populations of both naïve cells and cells that had been differentiating for 48 hours or more (Fig. 3F).

We next investigated whether any correlation existed between the levels of H2A.Zac and H3K9me2 at the nuclear periphery, and how these changes related to pluripotency loss. We performed simultaneous immunostaining of H2A.Zac and H3K9me2 with Lamin A. We located cells that still possessed some peripheral enrichment for H2A.Zac at 24 hours post differentiation, and compared their peripheral profiles to neighboring cells in the same image that had undergone H2A.Zac reduction. We found a positive correlation between $\mathrm{H} 2 \mathrm{~A}$.Zac reduction, $\mathrm{H} 3 \mathrm{~K} 9 \mathrm{me} 2$ accumulation, and differentiation status as judged by the intensity of the peripheral Lamin A border (Fig. 4).

Lamin A is not necessary for peripheral chromatin gradual expression and localization of Lamin A at 48 hours after TBL differentiation coincides with re-appearance of H3K9me2 at the periphery, we hypothesized that Lamin A might be a factor influencing the dynamic changes of H3K9me2 localization to the nuclear periphery. To test this, we used CRISPR to generate a hESC line with a homozygously disrupted Lmna gene (Fig. 5A). Lmna ${ }^{-/-}$hES cells proliferated normally and did not manifest any morphological differences compared to control cells under normal culturing conditions (Fig. S4). Immunofluorescence microscopy showed a complete loss of Lamin A staining in knockout cells, in contrast to the typical nuclear rim staining visible in unedited cells (Fig. 5B). Despite the loss of Lamin A, no qualitative differences in $\mathrm{H} 3 \mathrm{~K} 9 \mathrm{me} 2$ localization or intensity could be seen between homozygous knockout and unedited cells upon TBL induction (Fig. 5C, D). Lmna ${ }^{-/}$hES cells were able to differentiate into other lineages, including beating cardiomyocytes and neural progenitor cells (NPC) by directed differentiation induction (Supplemental Movie $\mathbf{1}$ and data not shown). We therefore conclude that although Lamin A localization in hESC is highly correlated with H3K9me2 at the periphery, it is not required for its localization.

The localization of HAT and HDAC proteins is dynamic as hESCs differentiate. We next wondered how H2A.Zac 


\section{Figure 3}

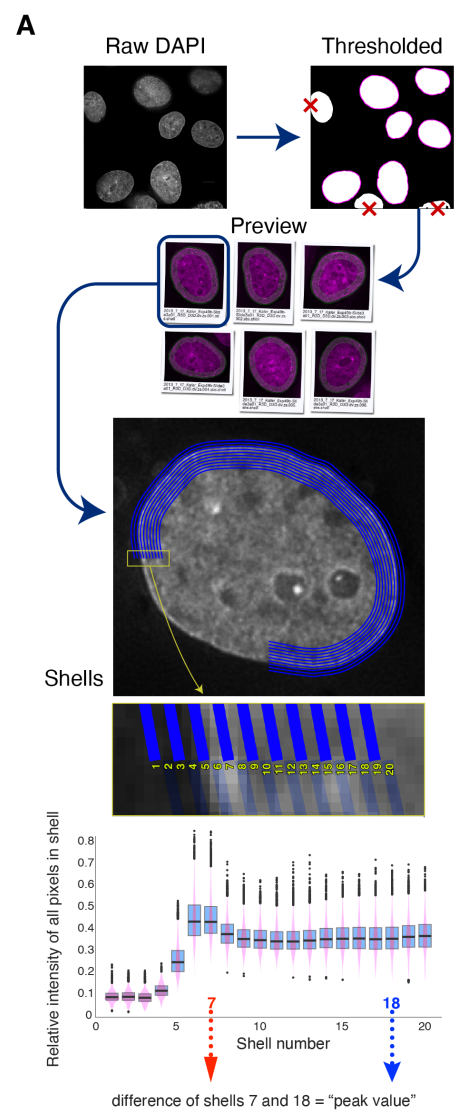

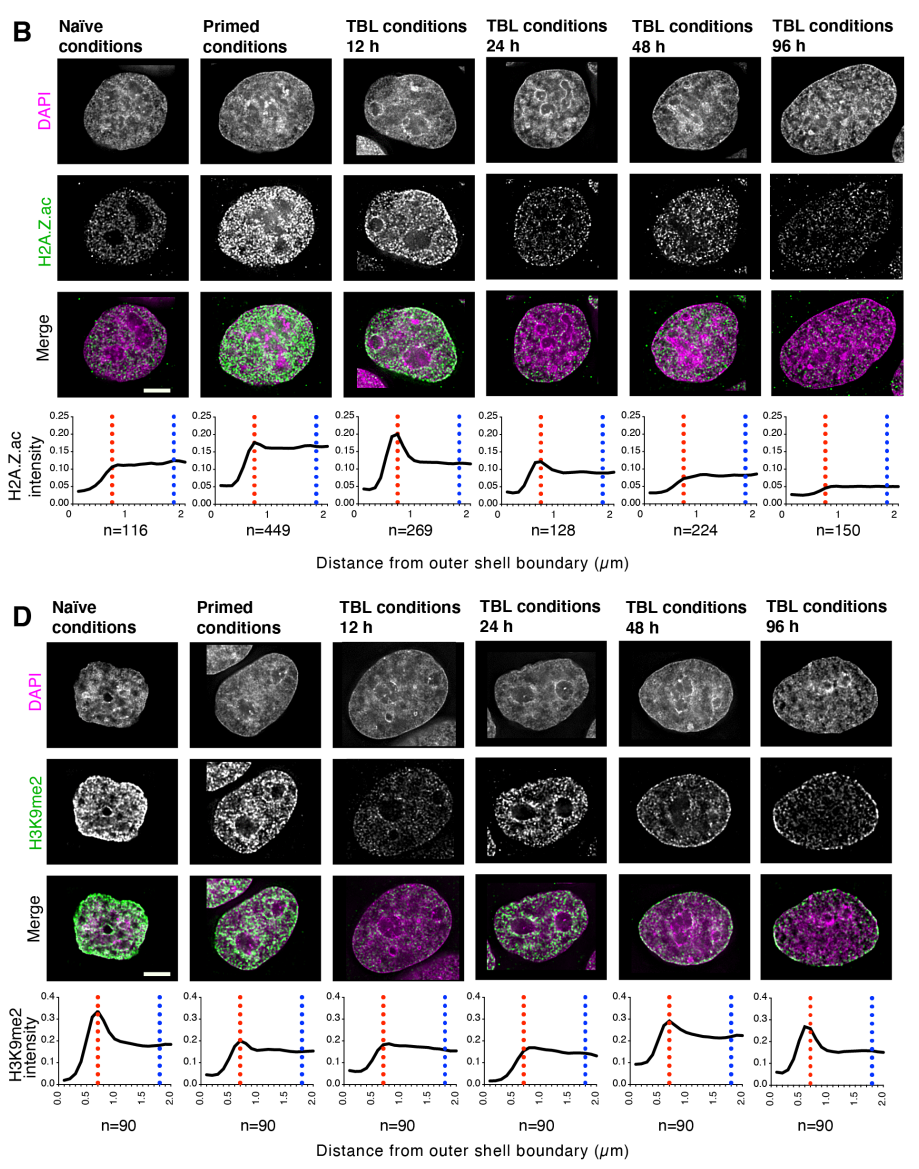

C
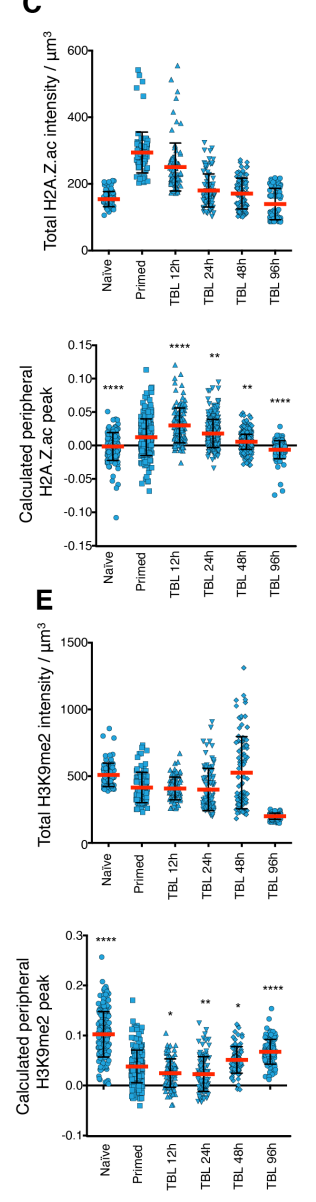

Fig. 3. H2A.Z acetylation and $\mathrm{H} 3 \mathrm{~K} 9 \mathrm{me} 2$ are alternately enriched at the nuclear periphery during differentiation. A, illustration of the shell-averaging procedure. The DAPI image is used to define a set of concentric shells spanning the nuclear periphery. The intensity of chromatin markers within each shell is averaged for the number of cells indicated underneath each graph; the difference between shells 7 and 18 is used to calculate the peak value. B, immunofluorescence examples of H2A.Zac under different differentiation conditions (top) and plots of shell-averaged intensity; cells and graphs shown are those nearest the average peak value for their class. C, plots of total intensity (top) and peak values (bottom) of H2A.Zac for all cells: $\mathrm{n}=(116,449,269,128,224,150)$ from left to right. D, immunofluorescence examples of H3K9me2 and corresponding plots, under the same conditions shown in B. E, plots of total intensity (top) and peak values (bottom) of H3K9me2 for all cells: $\mathrm{n}=90$ cells for all conditions. Scale bars, $5 \mu \mathrm{m}$

levels were changed by acetylation (i.e. histone acetyltransferase (HAT) activity) versus deacetylation (i.e. histone deacetylase (HDAC) activity). We reasoned that if histone modifications were enriched at the nuclear periphery, then the enzymes responsible for them may also be cytologically detectable in the same location. Previous work suggests that Tip60 is the primary HAT catalyzing H2A.Z acetylation (20, 32, 33), and while the identity of HDACs responsible for deacetylation of H2A.Zac is not known, it is likely to be a member of the "Class I" HDACs, HDAC1, HDAC2 or HDAC3 (34). HDAC1 and HDAC2 are known to be required for self-renewal and differentiation in ES and TS cells; however, the role of HDAC1 seems to be more critical (35-37).

We found that in primed hESC, Tip60 existed in 3 primary patterns, as central nucleoplasmic clusters surrounding DAPI enriched areas; as diffuse nucleoplasmic foci with no clear enrichment pattern; or, as nucleoplasmic foci with a tendency for enrichment at the nuclear periphery (Fig. S5C). Each specific Tip60 pattern could be found in cells at $12 \mathrm{~h}$ and $24 \mathrm{~h}$
post-TBL induction as well; however, the proportion of nuclei possessing different localisations changed, with primed hESC showing greater tendency toward peripheral localization than naïve or differentiating cells. In contrast, HDAC proteins displayed mostly homogeneous nuclear localization by immunofluorescence. We found that both HDAC1 and HDAC2 were localized to the nucleus in hESC. HDAC2 was stained intensely in hESC nuclei (Fig. 6A), while HDAC1 presented as small foci throughout the nucleoplasm (Fig. S5A). HDAC3 was not significantly enriched in the nucleus of pluripotent hESCs but did become nuclear 48 hours after cells were subjected to TBL induction (Fig. S5B). HDAC1 levels appeared to drop as hESCs began to differentiate (Fig. S5A) while HDAC2 levels were retained throughout differentiation, with some increased signal at 12 and $24 \mathrm{~h}$ post TBL induction (Fig. 6B). Of the HDACs we surveyed, therefore, the expression pattern of HDAC 2 most closely tracks the loss of H2A.Zac at the periphery.

The modifier specifically responsible for catalyzing $\mathrm{H} 3 \mathrm{~K} 9$ 


\section{Figure 4}
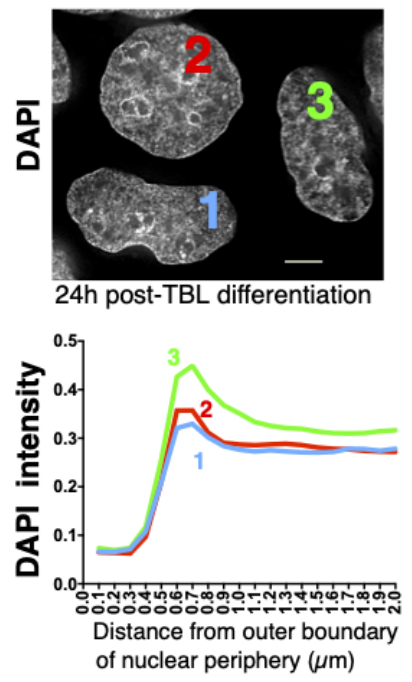
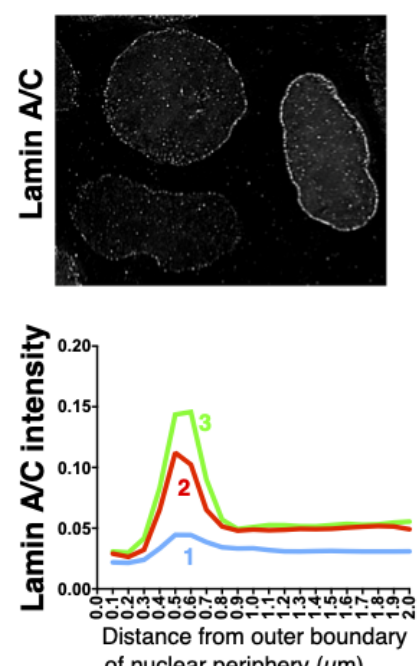

of nuclear periphery $(\mu \mathrm{m})$
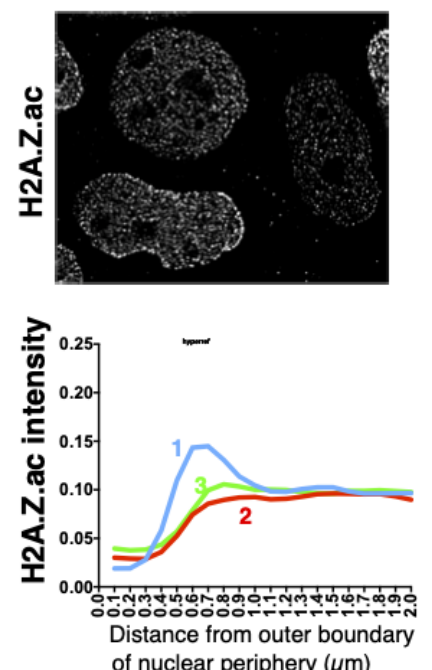

of nuclear periphery $(\mu \mathrm{m})$
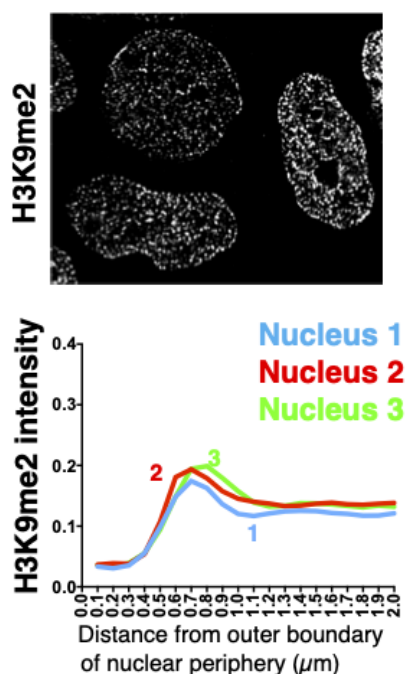

of nuclear periphery $(\mu \mathrm{m})$

Fig. 4. Comparison of individual cells at the same differentiation timepoint shows alternation of H2A.Zac and H3K9me2 peripheral intensity. Cells shown stained with DAPI and immunofluorescence as indicated; shell-averaged intensity graphs are shown for each numbered cell. Scale bar, $5 \mu \mathrm{m}$.

dimethylation is the histone methyl-transferase (HMTase) G9a (38). In primed hESC, G9a was detected by immunostaining as small nuclear foci throughout the cell nucleus (Fig. 6C). G9a location tracked that of H3K9me2 from 24 hours post differentiation, with a significant increase in G9a intensity throughout the nucleoplasm and a measurable increase in G9a signal at the nuclear periphery in $\mathrm{hESC}$ at 24 and 48 hours post differentiation (Fig. 6D). Together, our data suggests that HAT, HDAC and HMTase complexes responsible for changes in H2A.Z acetylation status and H3K9 methylation status also exhibit dynamic changes in their localization during pluripotency loss and early phases of differentiation.

\section{Acetylation of H2A.Z and dimethylation of H3K9 at the nuclear periphery is driven by histone modifiers and is essential for the progression of differentiation.} We next asked whether pharmacologically inhibiting histone modification enzymes would affect the localization of histone marks, and subsequently pluripotency loss and/or differentiation. We performed a series of experiments using the HDAC inhibitor TSA, a global inhibitor of Class I HDACs (39) expected to inhibit HDAC1, HDAC2 and HDAC3. Cells were first subjected to TBL differentiation, and then exposed to $12.5 \mathrm{nM}$ TSA for either $12 \mathrm{~h}$ or $36 \mathrm{~h}$ before sampling; control cells without TSA were sampled in parallel (Fig. 7A). Inhibition with TSA is reversible, and does not alter HDAC protein levels nor association, only deacetylation kinetics (40). This allowed us to indirectly interpret gains in histone acetylation in different nuclear compartments as locations where Class I HDAC complexes would usually be active (Fig. 7B). To determine if HDAC activity drives H2A.Zac removal from the nuclear periphery during differentiation, hES cells were induced to differentiate and treated with TSA at 12 hours, when peripheral H2A.Zac is elevated yet global levels have begun to decline. Under these conditions, H2A.Zac remained enriched at the nuclear periphery and $\mathrm{H} 3 \mathrm{~K} 9 \mathrm{me} 2$ signal at the periphery did not increase even after 48 hours of growth under differentiation conditions (Fig. 7C,D).Lamin A at the nuclear periphery was also less intense in treated cells, suggesting that TSA-treated hESC did not differentiate (Fig. 7E). These results suggest that HDAC activity, which appears to drive H2A.Zac removal from the nuclear periphery, is required for the normal progression of differentiation.

\section{Conclusions}

By quantitatively measuring the intranuclear distribution of histone modifications and variants during TBL differentiation, we find that H2A.Zac and H3K9me2 are the most significantly altered. H2A.Zac transiently elevates at the nuclear periphery of hESCs just prior to loss of pluripotency, but is then lost; whereas from day 2 of differentiation, H3K9me2 becomes peripherally elevated instead. We have shown that ongoing HDAC activity is responsible for removing H2A.Zac from the nuclear periphery at the onset of differentiation, and that HDAC activity is essential for differentiation to proceed. From analysis of the transcriptional activation and repression of the androgen receptor system (21,33), Giaimo (18) have proposed that H2A.Z, and especially ubiquitinated H2A.Z, can be repressive, but $\mathrm{H} 2 \mathrm{~A} . \mathrm{Z}$ acetylation leads to its deubiquitination and consequent activation of genes. Our finding that the nuclear periphery is specifically and transiently enriched for H2A.Z acetylation in the early stages of pluripotency loss of human ES cells suggests that upon differentiation, many genes normally found at the periphery, a generally repressive compartment, may rapidly transit to an active state through the action of H2A.Z-specific acetyltransferases. While the current study does not identify the genes that may be so regulated, it predicts that many genes whose activation is regulated by H2A.Z acetylation during TBL differentiation are likely to be found in hES cell Lamin-associated domain (LAD) compartments. 
bioRxiv preprint doi: https://doi.org/10.1101/2020.02.15.951103; this version posted February 16,2020 . The copyright holder for this preprint (which was not certified by peer review) is the author/funder, who has granted bioRxiv a license to display the preprint in perpetuity. It is made available under aCC-BY-NC-ND 4.0 International license.

Figure 5

A
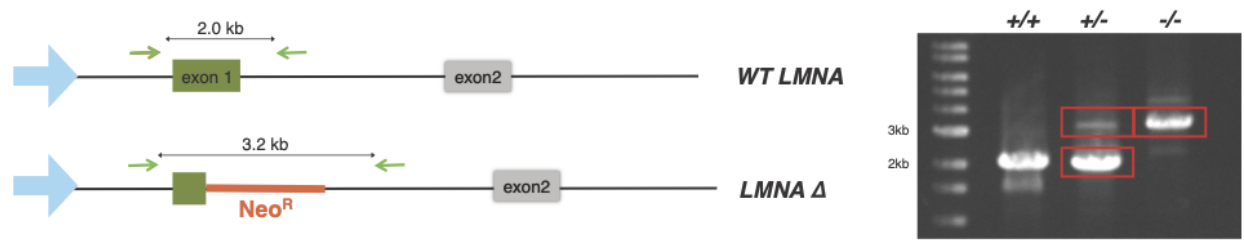

B

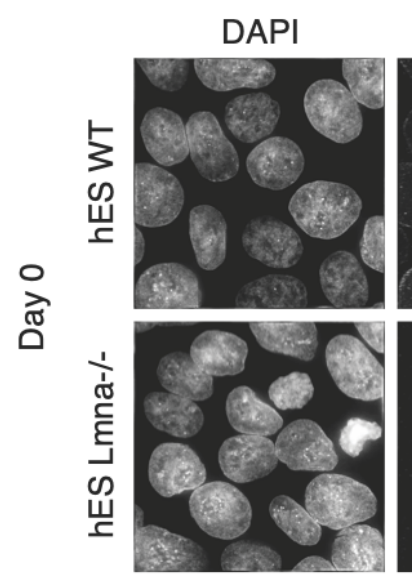

Lamin A

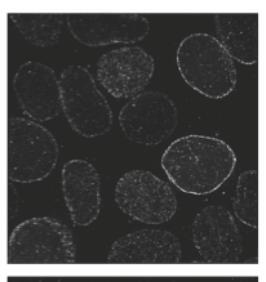

Lamin B

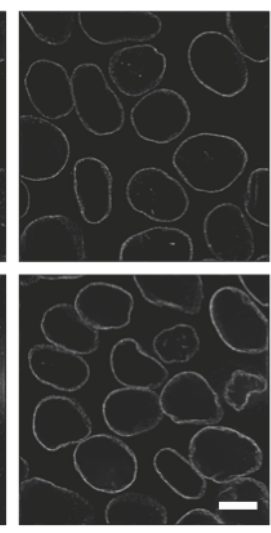

C
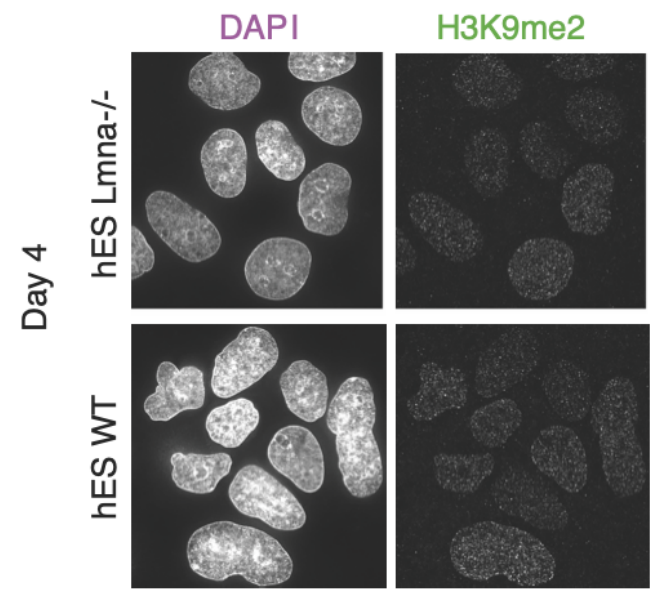

\section{Merged}
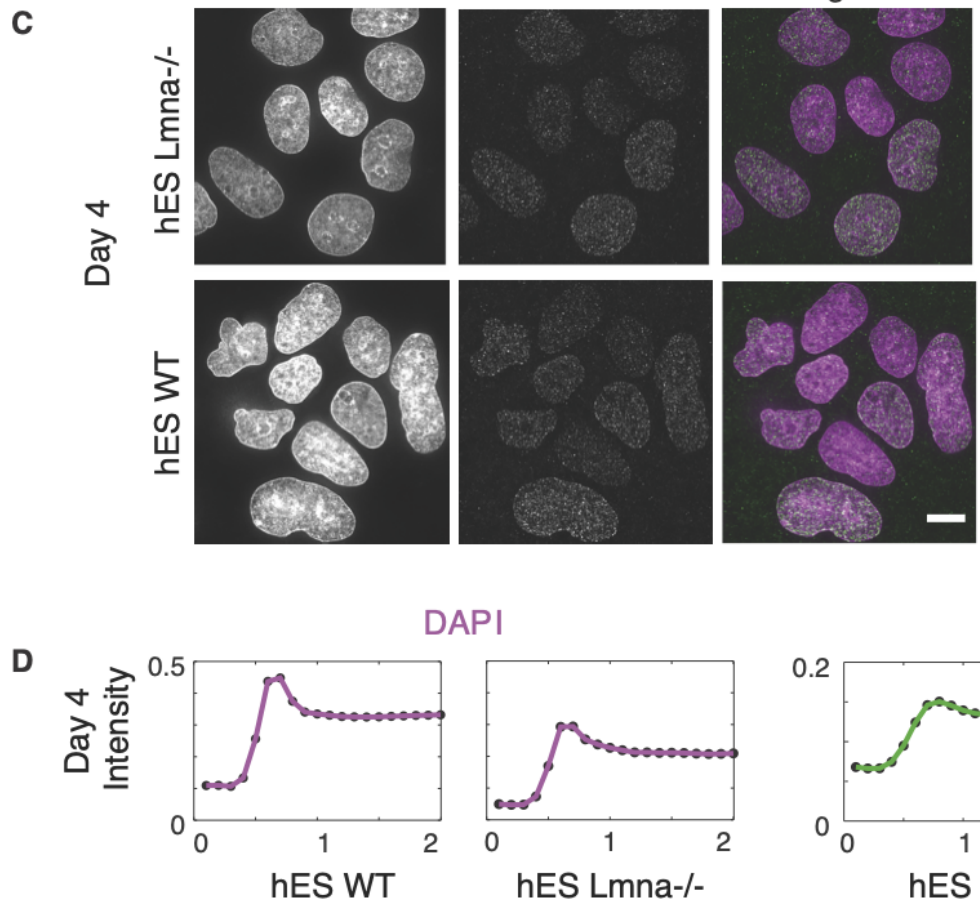

DAPI
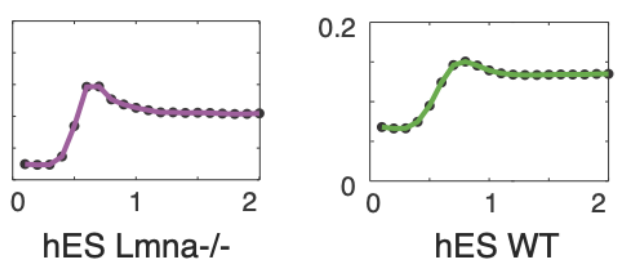

H3K9me2

Distance from outermost shell, $\mu \mathrm{m}$

Fig. 5. Lamin A does not play a role in H3K9me2 dynamics during TBL differentiation. A, Illustration of gene editing to remove the LmnA gene. CRISPR was used to replace the first exon of LmnA with a neomycin resistance cassette, disrupting the gene; hetero- and homozygous deletions were detected by PCR as shown (right). B, WT hES cells (top) and Lmna ${ }^{-/}$hES cells (bottom) stained for DAPI, Lamin A, and Lamin B. C, DAPI and H3K9me2 staining in WT hES cells (top) and Lmna ${ }^{-/}$hES cells (bottom) 4 days post-TBL differentiation. D, Quantitation of DAPI and H3K9me2 peripheral shell staining in WT hES cells and Lmna ${ }^{-1-} \mathrm{hES}$ cells as indicated. Scale bars, $5 \mu \mathrm{m}$.

Other studies have assayed the subnuclear distribution of histone modification marks, including $\mathrm{H} 3 \mathrm{~K} 4 \mathrm{me} 2$ and me3, H3K9me1, me2 and me3, H3K9ac, H3K27me2 and me3 and H3K79me1, in pluripotent and differentiated hESCs induced to differentiate by non-directed means. These studies reported that the only histone modifications which exhibited changes in radial distribution were $\mathrm{H} 3 \mathrm{~K} 9 \mathrm{me} 3, \mathrm{H} 3 \mathrm{~K} 9 \mathrm{ac}$ and H3K79me1, which were described as being reduced at the 
A

\section{Figure 6}

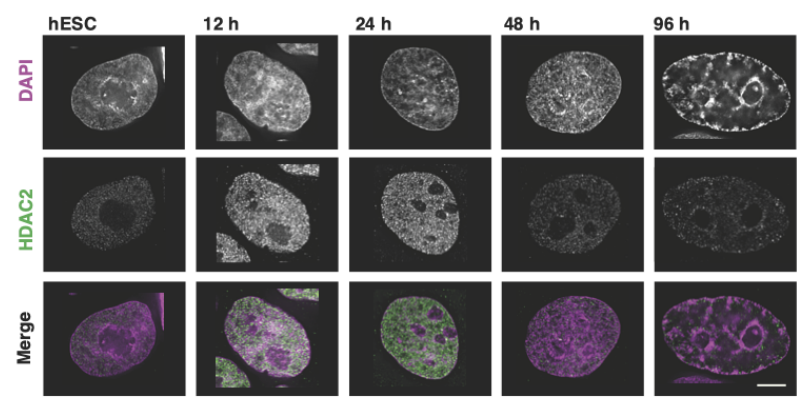

C
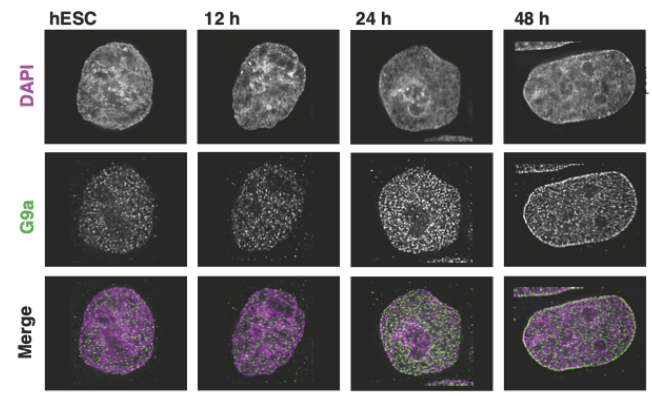

B

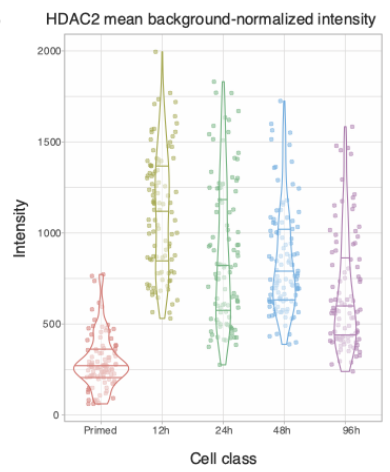

D

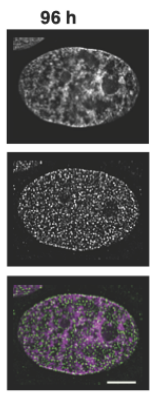

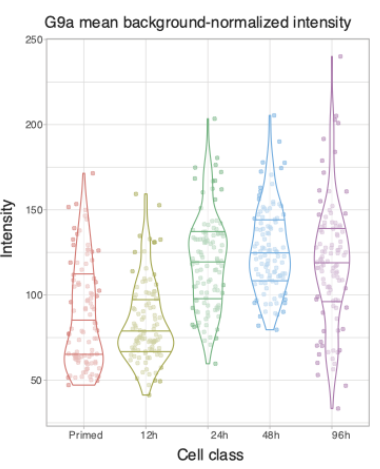
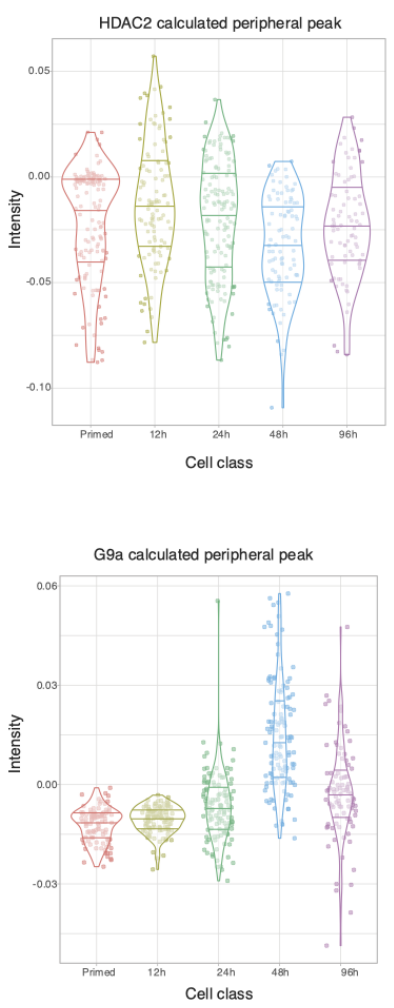

Fig. 6. HDAC2 and G9a display dynamic localization during TBL differentiation. A, Representative images of HDAC2 immunostaining during a TBL differentiation time course. B, quantitation of mean background-corrected intensity of HDAC2 for all nuclei at each timepoint (left) as well as the peak value calculated by subtracting the mean of shell 18 from shell 7 (right). All data points are shown as dots; distribution density shown by violin plot. $n=(104,102,101,112,98)$ cells measured from left to right. C, representative images of G9a immunostaining during TBL differentiation. D, mean background-corrected intensity of G9a for all nuclei at each timepoint (left) as well as the corresponding peak values (right). For both HDAC2 and G9a, the image chosen for each timepoint is closest to the mean value for total intensity. $n=(100,103,108,105,104)$ cells measured from left to right. Scale bars, $5 \mu \mathrm{m}$.

nuclear periphery (22). However our results showed that H3K9ac and H3K9me3 showed no significant location differences as hESCs lose pluripotency. These discrepancies could arise from differences in differentiation protocols and fate (our TBL protocol versus non-directed differentiation) as well as the image analysis methods used to calculate peripheral enrichment. In our method, we use an algorithm to define the periphery of the nucleus based on thresholded DAPI staining, and then assign shells by distance working inwards, as compared to the method employed by (22), wherein radial shells were established working outwards from the nucleus center. It is likely, however, that the particular histone marks enriched in the periphery vary, as commitment to different lineages involves different signals and transcriptional programs.

Treating primed hESC with the HDAC inhibitor TSA caused persistent and increased intensity of H2A.Zac throughout the nucleoplasm and at the nuclear periphery. This suggests that there is constant, active de- and re-acetylation in the pluripotent ES cell, including at the periphery. In addition to persistent H2A.Zac at the periphery, H3K9me2 appearance at the periphery was correspondingly delayed in TSA-treated cells, suggesting that the two histone modifications are regulated by linked mechanisms that trigger upon pluripotency loss.

In conclusion, we have shown evidence that the redistribution of two chromatin modifications (H2AZac and H3K9me2) at the nuclear periphery is a hallmark of pluripotency loss and/or differentiation. We have shown that Lamin A is not necessary for the alternation of H2A.Zac and H3K9me2 at the periphery during TBL differentiation. We have also shown through cytological analysis that H2A.Zac in general negatively correlates with $\mathrm{H} 3 \mathrm{~K} 9 \mathrm{me} 2$. We suggest that in the naïve $\mathrm{hESC}, \mathrm{H} 3 \mathrm{~K} 9 \mathrm{me} 2$ exists at the periphery to reinforce the peripheral location of silenced genes. However, when the hESC cell enters a primed state, Tip60 (or other H2A.Z acetylase) activity is higher at the periphery, enabling H2A.Z to be rapidly acetylated at the periphery following HDAC 1 and/or HDAC2 reduction upon pluripotency loss. This could be to prevent a premature accumulation of $\mathrm{H} 3 \mathrm{~K} 9 \mathrm{me} 2$ at the nuclear periphery, thereby ensuring the proper restructuring of chromatin upon lineage commitment and the refinement of key regulating elements such as LADs. Future work using singlecell ChIP-Seq analysis of histone marks could determine the identity of the genes regulated by the peripheral changes we observe and give important clues into compartment-specific gene regulation during differentiation. 
bioRxiv preprint doi: https://doi.org/10.1101/2020.02.15.951103; this version posted February 16, 2020. The copyright holder for this preprint (which was not certified by peer review) is the author/funder, who has granted bioRxiv a license to display the preprint in perpetuity. It is made available under aCC-BY-NC-ND 4.0 International license.

\section{Figure 7}

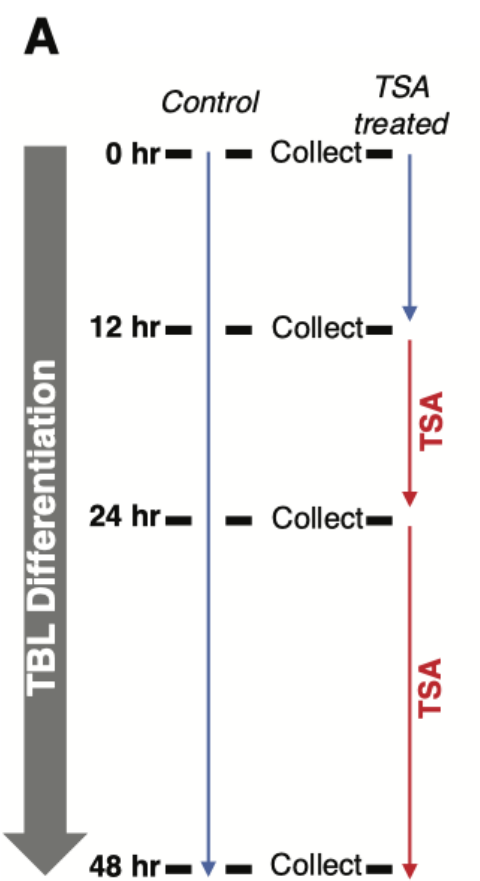

B
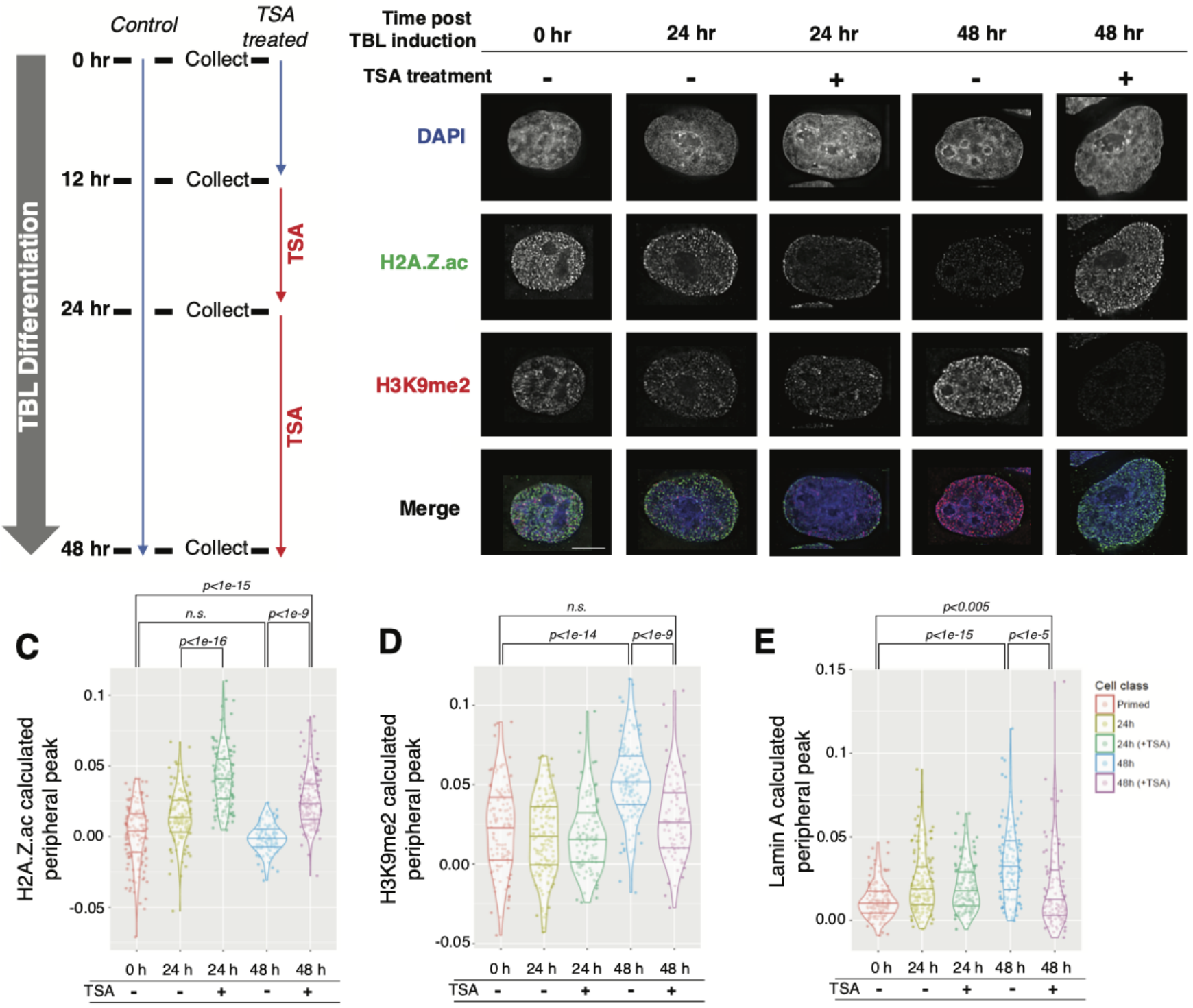

Fig. 7. TSA treatment prevents differentiation-associated changes in H2A.Z acetylation. A, schematic of treatment and collection times. TBL differentiation begins at time t0. B, representative images of nuclei immunostained for H2A.Zac and H3K9me2. C, peak values of H2A.Zac calculated for individual cells; $n=142,128,141,101,149$ from left to right. D, peak values of H3K9me2 calculated for individual cells: $n=116,153,102,121,81$ from left to right. $E$, peak values of Lamin A calculated for individual cells: $n=134,153,129,122,111$ from left to right. Scale bars, $5 \mu \mathrm{m}$. Significance values assessed with two-tailed $t$ test.

\section{Methods}

Cell Culture. Primary mouse embryonic fibroblast (MEF) cells were grown under standard conditions $(5 \% \mathrm{CO} 2$ humidified environment at $37^{\circ} \mathrm{C}$ ) in DMEM media supplemented with $10 \%$ fetal bovine serum. Human ES cells (H1 line) were maintained in ReproCell Primate media supplemented with FGF2 StemBeads $(8 \mu \mathrm{L} / \mathrm{mL}$, Stem Cultures) on Mitomycin$\mathrm{C}$ inactivated MEFs and mechanically passaged every 5-7 days. Following methods described in (28), hESCs were induced to a naïve state by growing cells in "naïve Human Stem Cell Media" (NHSM) which was ReproCell Primate media containing LIF (20 ng / mL), TGF $\beta$ (1ng / mL), FGF2 (8

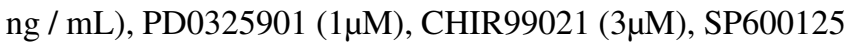
$(10 \mu \mathrm{M})$ and SB203580 $(10 \mu \mathrm{M})(28)$. NHSM media was added to hESCs 3 days post passage, and cells were allowed to grow for 2 days before a subsequent passage. Cells were then grown for a further 5 days in NHSM and used as "naïve" hESCs after the next passage. To differentiate hESCs into trophoblast like (TBL) cells, hESCs were passaged onto MEFfree surfaces coated with ES grade matrigel (Fisher Scientific, Cat\# 354277) and grown in ReproCell FF2 media and supplemented with FGF2 StemBeads. TBL differentiation was induced by removing hESC media and growing cells

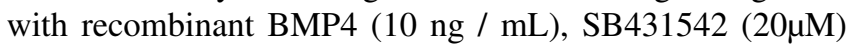




\begin{tabular}{llll}
\hline Antigen & Catalog Number & Source & Animal \\
\hline (pan)H2A.Z & ab4174 & Abcam & Rabbit \\
H2A.Z (acetyl K4+K7+K11) & ab18262 & Abcam & Sheep \\
H3K9me2 & 39683 & Active Motif & Mouse \\
HDAC1 & ab109411 & Abcam & Rabbit \\
HDAC2 & ab7029 & Abcam & Rabbit \\
HDAC3 & ab16047 & Abcam & Rabbit \\
G9a/EHMT2(C6H3) & 3306 & Cell Signaling & Rabbit \\
Cytokeratin 7 & ab154334 & Abcam & Rabbit \\
Nanog & ab80892 & Abcam & Rabbit \\
Oct4 & ab19857 & Abcam & Rabbit \\
Lamin A/C (H-102) & SC-20680 & Santa Cruz & Rabbit \\
Lamin B: M20 & SC-6217 & Santa Cruz & Goat \\
hCG beta & ab9582 & Abcam & Mouse \\
GCM1 & ab88748 & Abcam & Mouse \\
SYNA (Syncytin A) & sc-50369 & Santa Cruz & Rabbit \\
H3K27ac & ab4729 & Abcam & Rabbit \\
H3K27me3 & 39536,39538 & Active Motif & Mouse
\end{tabular}

(H3K4me3, H3K9me3, H3K36me3 - mouse monoclonal, kindly provided by H. Kimura)

Table 1. Antibodies used

and SU5402 $(20 \mu \mathrm{M})$. For TSA treatments, TSA was added to media to a final concentration of $12.5 \mathrm{nM}, 12$ hours after the start of differentiation induction. Cardiomyocyte differentiation of WT and $\mathrm{Lmna}^{-/} \mathrm{hES}$ cells was performed using the inducing agent KY02111 according to protocols in (41).

Immunofluorescence. For experiments, cells were seeded onto glass coverslips or $35 \mathrm{~mm}$ glass bottom dishes (Matsunami\#1S) coated with ES grade matrigel (Fisher Scientific, Cat\# 354277) and fixed by incubation with 4\% PFA for 10 minutes at $4{ }^{\circ} \mathrm{C}$. Samples were washed with PBST and permeabilized with $0.5 \%$ Triton-X in PBS for 5 minutes at room temperature. Samples were washed again and incubated in blocking solution (2\% BSA in PBST), then incubated with primary antibodies (Table S1) diluted in block solution in a humidified chamber overnight at $4^{\circ} \mathrm{C}$. Samples were washed before incubation with secondary antibodies (Table S1) for 1 hour at room temperature, washed again and counterstained with DAPI for 5 minutes before being mounted onto microscope slides with $1 \% n$-propyl gallate in glycerol. Samples were stored at $-20^{\circ} \mathrm{C}$ prior to imaging.

RNA FISH. Cells were grown glass coverslips and fixed as per the immunofluorescence procedure described above. FISH probes (Stellaris) directed against human Nanog and Cdx2 (see Supplemental Data S1) were reconstituted in nuclease-free TE buffer to a concentration of $25 \mu \mathrm{M}$ and stored at $20^{\circ} \mathrm{C}$ prior to use. Cells were permeabilized with cold $70 \%$ ethanol for 1 hour before hybridization, washed in wash buffer (10\% formamide in $2 \mathrm{X}$ saline-sodium citrate (SSC) before hybridization was performed using probes diluted to $250 \mathrm{nM}$ in hybridization buffer $(10 \mathrm{mg} / \mathrm{mL}$ dextran sulfate, $10 \%$ formamide in $2 \mathrm{X} \mathrm{SSC}$ ) for 4 hours at $37^{\circ} \mathrm{C}$. Cells were then washed again, nuclei were counterstained with DAPI in 2X SSC for 5 minutes before mounting onto microscope slides with $1 \% n$-propyl gallate in glycerol. Samples were stored at $-20^{\circ} \mathrm{C}$ prior to imaging.

Fluorescence microscopy. Cells were imaged on a conventional wide-field DeltaVision deconvolution system (Applied Precision/GE Healthcare) using a 100x oil objective and immersion liquid of refractive index 1.513. Images were corrected for bleaching and lamp flicker, and processed with constrained iterative deconvolution using the softWoRx suite, using a point-spread function measured with $100 \mathrm{~nm}$ green fluorescent latex beads at a $\mathrm{Z}$ step size of 0.2 , to remove out-of-focus light. Axial aberration of different wavelengths was corrected through sub-pixel shifting in the $\mathrm{Z}$ direction based on peak axial positions of multicolor beads. Quantitative analysis of images was performed with the Fiji/ImageJ suite (42).

Knockout of LMNA gene.hES cells (H1) were thawed at P29 and transfected with $3.3 \mu \mathrm{M}$ of each hCas9D10A (Addgene \#74495), and a gRNA/donor plasmid (pUC_lmnA_Neo_exn1_donor_fixed containing gRNA sequence GCAGGAGCTCAATGATCGCTTGG; see Supplemental data S2) using Lipofectamine 2000 as per instructions. Cells were rescued and grown in the presence of ROCK inhibitor overnight, then placed in normal hES media on Matrigel for 4 days. Subsequently, G418 was added at $200 \mu \mathrm{g} / \mathrm{ml}$ to select for Neo+ cells. After 2-3 days, cells were passaged to plates containing inactivated feeder MEF cells. After four days of colony growth, individual colonies were picked and grown in 24-well plates. Colonies were then sampled and screened by PCR for deletion. After establishment of the $\mathrm{Lmna}^{-/}$cell line, PCR and sequencing was carried out on a selection of sites in coding regions containing the nearest homology to the gRNA sequence, and no changes were found (data not shown). Primers used to screen for deletion were lmnA_nested_fwd [5'gggactgaagggggaagg3'] 
bioRxiv preprint doi: https://doi.org/10.1101/2020.02.15.951103; this version posted February 16,2020 . The copyright holder for this preprint (which was not certified by peer review) is the author/funder, who has granted bioRxiv a license to display the preprint in perpetuity. It is made available under aCC-BY-NC-ND 4.0 International license.

and lmnA_out_rev [5' cactctgcgtgtctggg 3'], expected to give $2 \mathrm{~kb}$ in WT cells but a $3.2 \mathrm{~kb}$ band in deletion cells.

Periphery distance analysis. : For each nucleus, an absolute nuclear periphery was determined based on a smoothed, thresholded DAPI image. Calculating the Euclidean distance map inward from the threshold boundary and binning by $100 \mathrm{~nm}$ (1.56 pixel increments) enabled the generation of 20 peripheral "shells" of $100 \mathrm{~nm}$ each, beginning approximately $500 \mathrm{~nm}$ outside the periphery and covering a total of $2 \mu \mathrm{m}$ (see Fig. 3A). The average fluorescence intensity of Lamin A compares well with the peripheral distribution profile of DAPI staining, serving as an internal control for the shell analysis (Fig. S2). Code (GNU Octave and Perl) is provided at github.com/pmcarlton/shellanalysis.

Statistical analysis. All statistical analysis was performed using R version 3.4.4 (43) or Prism (GraphPad, Inc.) software.

\section{ACKNOWLEDGEMENTS}

We thank $\mathrm{H}$. Kimura for kindly providing monoclonal antibodies, N. Nakatsuji for guidance and resources in maintaining human ES cells, I. Minami for assistance with cardiomyocyte differentiation, and K. Hasegawa and A. Sato for critical reading and helpful discussions. This project was carried out in part through funds provided by the Inamori foundation and the Sumitomo foundation.

\section{Bibliography}

1. Daan Peric-Hupkes, Wouter Meuleman, Ludo Pagie, Sophia W M Bruggeman, Irina Solovei, Wim Brugman, Stefan Gräf, Paul Flicek, Ron M Kerkhoven, Maarten van Lohuizen, Marcel Reinders, Lodewyk Wessels, and Bas van Steensel. Molecular maps of the reorganization of genome-nuclear lamina interactions during differentiation. Mol. Cell, 38(4):603-613, May 2010.

2. Hitoshi Niwa. The pluripotency transcription factor network at work in reprogramming. Curr. Opin. Genet. Dev., 28:25-31, October 2014.

3. Ichiro Hiratani, Tyrone Ryba, Mari Itoh, Tomoki Yokochi, Michaela Schwaiger, Chia-Wei Chang, Yung Lyou, Tim M Townes, Dirk Schübeler, and David M Gilbert. Global reorganization of replication domains during embryonic stem cell differentiation. PLoS Biol., 6(10): e245, October 2008.

4. Pierre Therizols, Robert S Illingworth, Celine Courilleau, Shelagh Boyle, Andrew J Wood, and Wendy A Bickmore. Chromatin decondensation is sufficient to alter nuclear organization in embryonic stem cells. Science, 346(6214):1238-1242, December 2014.

5. R T O'Keefe, S C Henderson, and D L Spector. Dynamic organization of DNA replication in mammalian cell nuclei: spatially and temporally defined replication of chromosome-specific alpha-satellite DNA sequences. J. Cell Biol., 116(5):1095-1110, March 1992.

6. Asifa Akhtar and Susan M Gasser. The nuclear envelope and transcriptional control. Nat. Rev. Genet., 8(7):507-517, July 2007.

7. Jop Kind, Ludo Pagie, Havva Ortabozkoyun, Shelagh Boyle, Sandra S de Vries, Hans Janssen, Mario Amendola, Leisha D Nolen, Wendy A Bickmore, and Bas van Steensel. Single-cell dynamics of genome-nuclear lamina interactions. Cell, 153(1):178-192, March 2013.

8. Megan J Puckelwartz, Frederic Fs Depreux, and Elizabeth M McNally. Gene expression, chromosome position and lamin A/C mutations. Nucleus, 2(3):162-167, May 2011.

9. Benjamin D Towbin, Cristina González-Aguilera, Ragna Sack, Dimos Gaidatzis, Véronique Kalck, Peter Meister, Peter Askjaer, and Susan M Gasser. Step-wise methylation of histone H3K9 positions heterochromatin at the nuclear periphery. Cell, 150(5):934-947, August 2012.

10. Jan Padeken and Patrick Heun. Nucleolus and nuclear periphery: Velcro for heterochromatin. Curr. Opin. Cell Biol., 28:54-60, June 2014.

11. Jennifer $C$ Harr, Teresa Romeo Luperchio, Xianrong Wong, Erez Cohen, Sarah J Wheelan, and Karen $\mathrm{L}$ Reddy. Directed targeting of chromatin to the nuclear lamina is mediated by chromatin state and a-type lamins. J. Cell Biol., 208(1):33-52, January 2015.

12. Kelvin See, Yemin Lan, Joshua Rhoades, Rajan Jain, Cheryl L Smith, and Jonathan A Epstein. Lineage-specific reorganization of nuclear peripheral heterochromatin and $\mathrm{H} 3 \mathrm{~K} 9 \mathrm{me} 2$ domains. Development, 146(3), February 2019.

13. Irina Solovei, Audrey S Wang, Katharina Thanisch, Christine S Schmidt, Stefan Krebs, Monika Zwerger, Tatiana V Cohen, Didier Devys, Roland Foisner, Leo Peichl, Harald Herrmann, Helmut Blum, Dieter Engelkamp, Colin L Stewart, Heinrich Leonhardt, and Boris Joffe. LBR and lamin A/C sequentially tether peripheral heterochromatin and inversely regulate differentiation. Cell, 152(3):584-598, January 2013.

14. Hyemin Kim, Mi-Jin Jang, Man-Jong Kang, and Yong-Mahn Han. Epigenetic signatures and temporal expression of lineage-specific genes in hESCs during differentiation to hepatocytes in vitro. Hum. Mol. Genet., 20(3):401-412, February 2011.
15. Michael Sachs, Courtney Onodera, Kathryn Blaschke, Kevin T Ebata, Jun S Song, and Miguel Ramalho-Santos. Bivalent chromatin marks developmental regulatory genes in the mouse embryonic germline in vivo. Cell Rep., 3(6):1777-1784, June 2013.

16. Xiaoji Chen, Kyobi Skutt-Kakaria, Jerry Davison, Yang-Li Ou, Edward Choi, Punam Malik, Keith Loeb, Brent Wood, George Georges, Beverly Torok-Storb, and Patrick J Paddison. G9a/GLP-dependent histone H3K9me2 patterning during human hematopoietic stem cell lineage commitment. Genes Dev., 26(22):2499-2511, November 2012.

17. Florian Lienert, Fabio Mohn, Vijay K Tiwari, Tuncay Baubec, Tim C Roloff, Dimos Gaidatzis, Michael B Stadler, and Dirk Schübeler. Genomic prevalence of heterochromatic H3K9me2 and transcription do not discriminate pluripotent from terminally differentiated cells. PLOS Genet., 7(6):e1002090, June 2011.

18. Benedetto Daniele Giaimo, Francesca Ferrante, Andreas Herchenröther, Sandra B Hake, and Tilman Borggrefe. The histone variant H2A.Z in gene regulation. Epigenetics Chromatin, 12(1):37, June 2019.

19. Kimberley Bruce, Fiona A Myers, Evangelia Mantouvalou, Pascal Lefevre, Ian Greaves, Constanze Bonifer, David J Tremethick, Alan W Thorne, and Colyn Crane-Robinson. The replacement histone H2A.Z in a hyperacetylated form is a feature of active genes in the chicken. Nucleic Acids Res., 33(17):5633-5639, October 2005.

20. Michael-Christopher Keogh, Thomas A Mennella, Chika Sawa, Sharon Berthelet, Nevan J Krogan, Adam Wolek, Vladimir Podolny, Laura Rocco Carpenter, Jack F Greenblatt, Kristin Baetz, and Stephen Buratowski. The saccharomyces cerevisiae histone H2A variant htz1 is acetylated by NuA4. Genes Dev., 20(6):660-665, March 2006.

21. Fátima Valdés-Mora, Cathryn M Gould, Yolanda Colino-Sanguino, Wenjia Qu, Jenny Z Song, Kylie M Taylor, Fabian A Buske, Aaron L Statham, Shalima S Nair, Nicola J Armstrong, James G Kench, Kenneth M L Lee, Lisa G Horvath, Minru Qiu, Alexei llinykh, Nicole S Yeo-Teh, David Gallego-Ortega, Clare Stirzaker, and Susan J Clark. Acetylated histone variant H2A.Z is involved in the activation of neo-enhancers in prostate cancer. Nat. Commun., 8(1):1346, November 2017.

22. Eva Bártová, Gabriela Galiová, Jana Krejcí, Andrea Harnicarová, Ludek Strasák, and Stanislav Kozubek. Epigenome and chromatin structure in human embryonic stem cells undergoing differentiation. Dev. Dyn., 237(12):3690-3702, December 2008.

23. Mitsuyoshi Amita, Katsuyuki Adachi, Andrei P Alexenko, Sunilima Sinha, Danny J Schust, Laura C Schulz, R Michael Roberts, and Toshihiko Ezashi. Complete and unidirectional conversion of human embryonic stem cells to trophoblast by BMP4. Proc. Natl. Acad. Sci. U. S. A., 110(13):E1212-21, March 2013

24. Smita Sudheer, Raghu Bhushan, Beatrix Fauler, Hans Lehrach, and James Adjaye. FGF inhibition directs BMP4-mediated differentiation of human embryonic stem cells to syncytiotrophoblast. Stem Cells Dev., 21(16):2987-3000, November 2012.

25. Diane I Schroeder, John D Blair, Paul Lott, Hung On Ken Yu, Danna Hong, Florence Crary, Paul Ashwood, Cheryl Walker, lan Korf, Wendy P Robinson, and Janine M LaSalle. The human placenta methylome. Proc. Natl. Acad. Sci. U. S. A., 110(15):6037-6042, April 2013.

26. Manisha Kar, Debabrata Ghosh, and Jayasree Sengupta. Histochemical and morphological examination of proliferation and apoptosis in human first trimester villous trophoblast. Hum. Reprod., 22(11):2814-2823, November 2007.

27. Miki Mori, Gen Ishikawa, Shan-Shun Luo, Takuya Mishima, Tadashi Goto, John M Robinson, Shigeki Matsubara, Toshiyuki Takeshita, Hiroaki Kataoka, and Toshihiro Takizawa. The cytotrophoblast layer of human chorionic villi becomes thinner but maintains its structural integrity during gestation. Biol. Reprod., 76(1):164-172, January 2007.

28. Ohad Gafni, Leehee Weinberger, Abed Alfatah Mansour, Yair S Manor, Elad Chomsky, Dalit Ben-Yosef, Yael Kalma, Sergey Viukov, Itay Maza, Asaf Zviran, Yoach Rais, Zohar Shipony, Zohar Mukamel, Vladislav Krupalnik, Mirie Zerbib, Shay Geula, Inbal Caspi, Dan Schneir, Tamar Shwartz, Shlomit Gilad, Daniela Amann-Zalcenstein, Sima Benjamin, Ido Amit, Amos Tanay, Rada Massarwa, Noa Novershtern, and Jacob H Hanna. Derivation of novel human ground state naive pluripotent stem cells. Nature, 504(7479):282-286, December 2013.

29. S Warrier, M Van der Jeught, G Duggal, L Tilleman, E Sutherland, J Taelman, M Popovic, S Lierman, S Chuva De Sousa Lopes, A Van Soom, L Peelman, F Van Nieuwerburgh, D I M De Coninck, B Menten, P Mestdagh, J Van de Sompele, D Deforce, P De Sutter, and $B$ Heindryckx. Direct comparison of distinct naive pluripotent states in human embryonic stem cells. Nat. Commun., 8:15055, April 2017.

30. Kallayanee Chawengsaksophak, Wim de Graaff, Janet Rossant, Jacqueline Deschamps, and Felix Beck. Cdx2 is essential for axial elongation in mouse development. Proc. Natl. Acad. Sci. U. S. A., 101(20):7641-7645, May 2004.

31. Dan Constantinescu, Heather L Gray, Paul J Sammak, Gerald P Schatten, and Antonei B Csoka. Lamin A/C expression is a marker of mouse and human embryonic stem cell differentiation. Stem Cells, 24(1):177-185, January 2006.

32. Andréanne Auger, Luc Galarneau, Mohammed Altaf, Amine Nourani, Yannick Doyon, Rhea T Utley, Dominique Cronier, Stéphane Allard, and Jacques Côté. Eaf1 is the platform for NuA4 molecular assembly that evolutionarily links chromatin acetylation to ATPdependent exchange of histone H2A variants. Mol. Cell. Biol., 28(7):2257-2270, April 2008.

33. Saya Ito, Naruhiro Kayukawa, Takashi Ueda, Hidefumi Taniguchi, Yukako Morioka, Fumiya Hongo, and Osamu Ukimura. MRGBP promotes AR-mediated transactivation of KLK3 and TMPRSS2 via acetylation of histone H2A.Z in prostate cancer cells. Biochim. Biophys. Acta Gene Regul. Mech., August 2018.

34. Geneviève P Delcuve, Dilshad H Khan, and James R Davie. Roles of histone deacetylases in epigenetic regulation: emerging paradigms from studies with inhibitors. Clin. Epigenetics, 4(1):5, March 2012

35. Oliver M Dovey, Charles T Foster, and Shaun M Cowley. Histone deacetylase 1 (HDAC1), but not HDAC2, controls embryonic stem cell differentiation. Proc. Natl. Acad. Sci. U. S. A., 107(18):8242-8247, May 2010.

36. Benjamin L Kidder and Stephen Palmer. HDAC1 regulates pluripotency and lineage specific transcriptional networks in embryonic and trophoblast stem cells. Nucleic Acids Res., 40 (7):2925-2939, April 2012.

37. S Jamaladdin, R D W Kelly, L O'Regan, O M Dovey, G E Hodson, C J Millard, N Portolano, A M Fry, J W R Schwabe, and S M Cowley. Histone deacetylase (HDAC) 1 and 2 are essential for accurate cell division and the pluripotency of embryonic stem cells. Proceedings 
bioRxiv preprint doi: https://doi.org/10.1101/2020.02.15.951103; this version posted February 16,2020 . The copyright holder for this preprint

(which was not certified by peer review) is the author/funder, who has granted bioRxiv a license to display the preprint in perpetuity. It is made available under aCC-BY-NC-ND 4.0 International license.

of the National Academy of Sciences, June 2014.

38. Makoto Tachibana, Kenji Sugimoto, Masami Nozaki, Jun Ueda, Tsutomu Ohta, Misao Ohki, Mikiko Fukuda, Naoki Takeda, Hiroyuki Niida, Hiroyuki Kato, and Yoichi Shinkai. G9a histone methyltransferase plays a dominant role in euchromatic histone $\mathrm{H} 3$ lysine 9 methylation and is essential for early embryogenesis. Genes Dev., 16(14):1779-1791, July 2002.

39. M Yoshida, M Kijima, M Akita, and T Beppu. Potent and specific inhibition of mammalian histone deacetylase both in vivo and in vitro by trichostatin a. J. Biol. Chem., 265(28): 17174-17179, October 1990.

40. Anoushe Sekhavat, Jian-Min Sun, and James R Davie. Competitive inhibition of histone deacetylase activity by trichostatin a and butyrate. Biochem. Cell Biol., 85(6):751-758, December 2007.

41. Itsunari Minami, Kohei Yamada, Tomomi G Otsuji, Takuya Yamamoto, Yan Shen, Shinya Otsuka, Shin Kadota, Nobuhiro Morone, Maneesha Barve, Yasuyuki Asai, Tatyana TenkovaHeuser, John E Heuser, Motonari Uesugi, Kazuhiro Aiba, and Norio Nakatsuji. A small molecule that promotes cardiac differentiation of human pluripotent stem cells under defined, cytokine- and xeno-free conditions. Cell Rep., 2(5):1448-1460, November 2012.

42. Johannes Schindelin, Ignacio Arganda-Carreras, Erwin Frise, Verena Kaynig, Mark Longair, Tobias Pietzsch, Stephan Preibisch, Curtis Rueden, Stephan Saalfeld, Benjamin Schmid, Jean-Yves Tinevez, Daniel James White, Volker Hartenstein, Kevin Eliceiri, Pavel Tomancak, and Albert Cardona. Fiji: an open-source platform for biological-image analysis. Nat. Methods, 9(7):676-682, July 2012.

43. R Core Team. R: A Language and Environment for Statistical Computing. R Foundation for Statistical Computing, Vienna, Austria, 2018. 
bioRxiv preprint doi: https://doi.org/10.1101/2020.02 15.951103; this version posted February 16, 2020. The copyright holder for this preprint (which was not certified by peer review) is the author/funder, who has granted bioRxiv a license to display the preprint in perpetuity. It is made available under aCC-BY-NC-ND 4.0 International license.

\section{Figure S1}

A

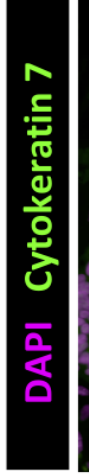

hESC conditions Day 4

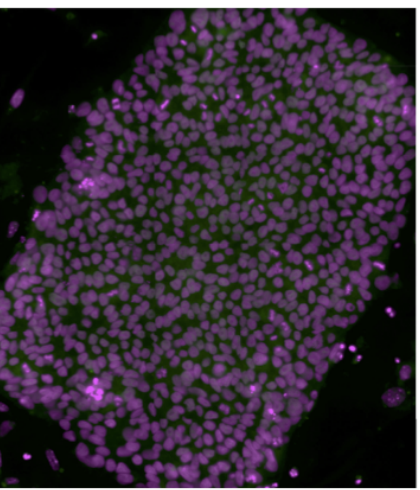

TBL conditions

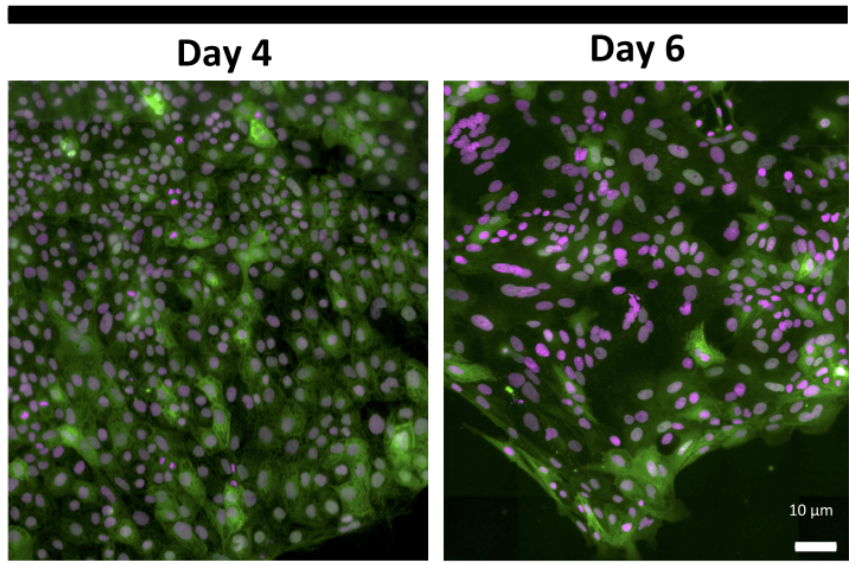

B

TBL conditions

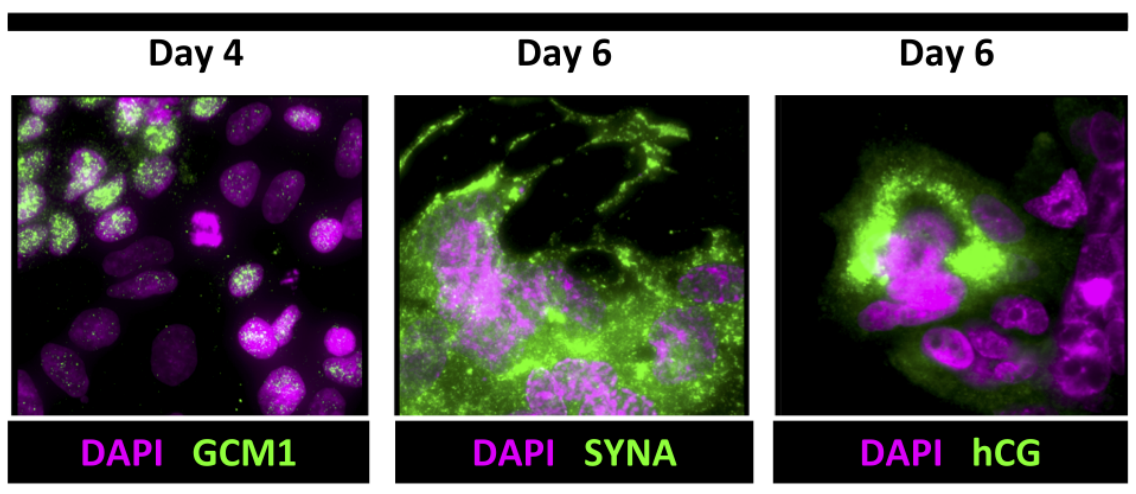

Supplemental Fig. 1. Immunofluorescence characterization of late-stage hES differentiation into a TBL fate. A, comparison of nondifferentiated (left) with differentiated day 4 (middle) and day 6 (right) cells, stained with DAPI (magenta) and Cytokeratin 7 (green). B, trophoblast biomarkers GCM1, Syncytin A, and hCG are immunostained in green. 
bioRxiv preprint doi: https://doi.org/10.1101/2020.02.15.951103; this version posted February 16,2020 . The copyright holder for this preprint (which was not certified by peer review) is the author/funder, who has granted bioRxiv a license to display the preprint in perpetuity. It is made available under aCC-BY-NC-ND 4.0 International license.

\section{Figure S2}

A TBL cell (Day 4)
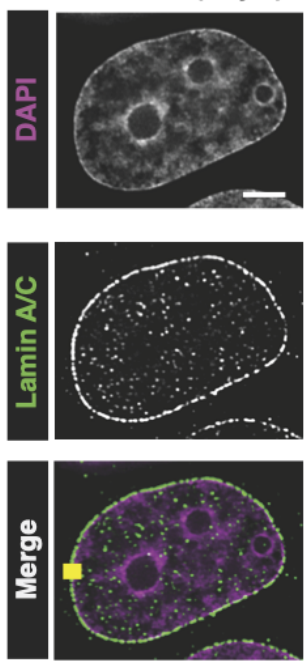

B

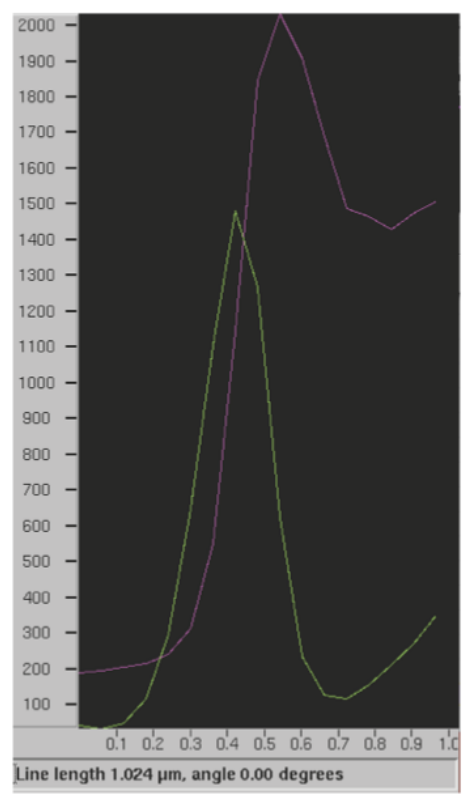

C

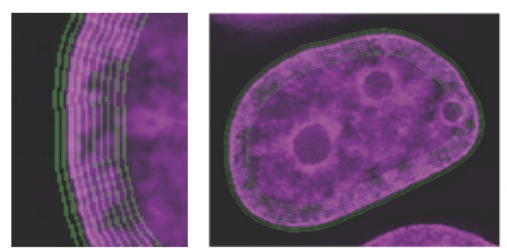

D

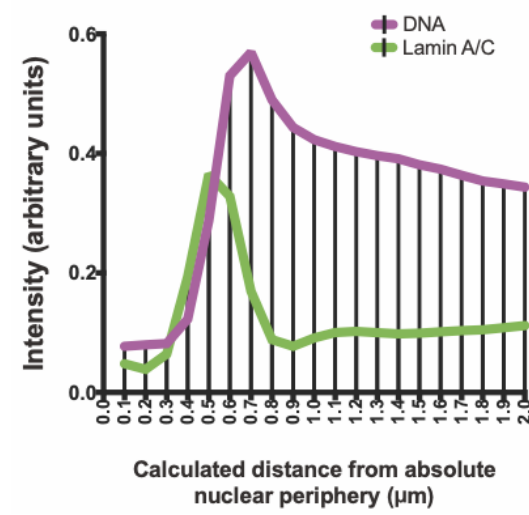

Supplemental Fig. 2. Illustration of shell averaging procedure and agreement with line profile. A, representative image of a hESderived cell nucleus after 4 days of TBL differentiation treatment, stained with DAPI (top), Lamin A (middle); merged image at bottom. The bottom image shows a yellow line where the line profile is taken in panel B. B, a line profile showing intensity of both DAPI (magenta) and Lamin A (green) immunostaining. C, illustration of the 20 peripheral shells detected and used for intensity averaging. D, average intensities within each shell, calculated automatically, show agreement with the manually-drawn line profile. 
bioRxiv preprint doi: https://doi.org/10.1101/2020.02.15.951103; this version posted February 16,2020 . The copyright holder for this preprint (which was not certified by peer review) is the author/funder, who has granted bioRxiv a license to display the preprint in perpetuity. It is made available under aCC-BY-NC-ND 4.0 International license.

\section{Figure S3}

\section{A}
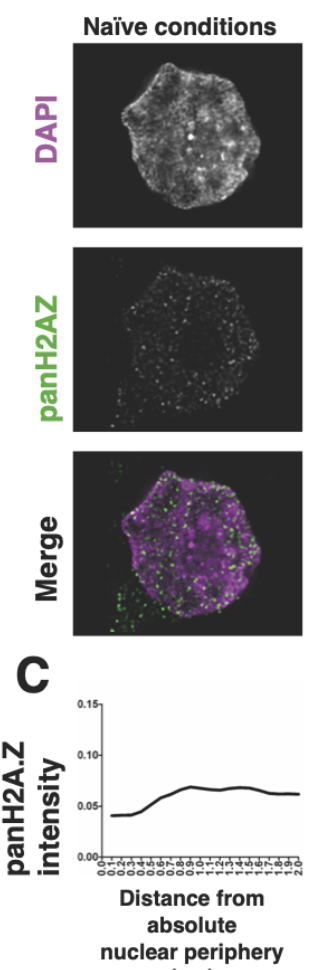

$(\mu \mathrm{m})$
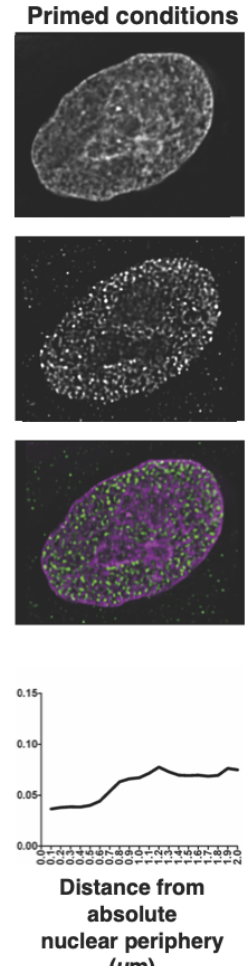

$(\mu \mathrm{m})$
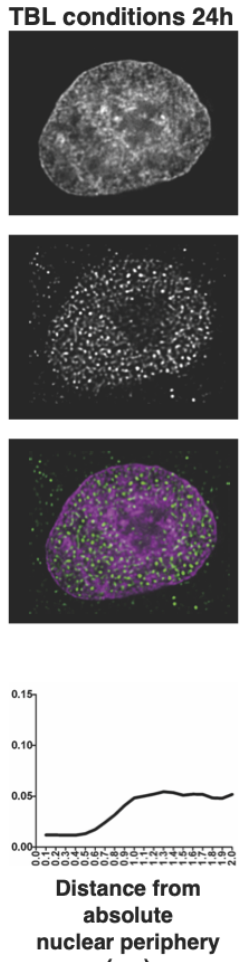

$(\mu \mathrm{m})$
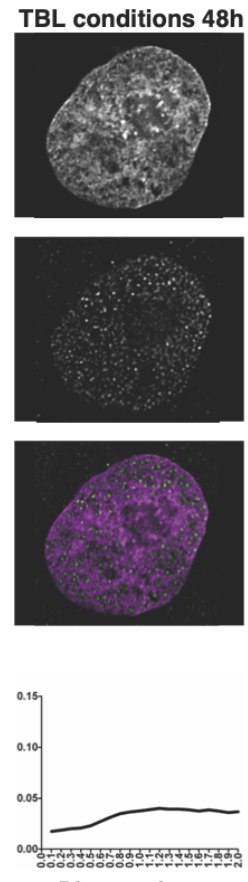

Distance from absolute nuclear periphery

$(\mu \mathrm{m})$
B
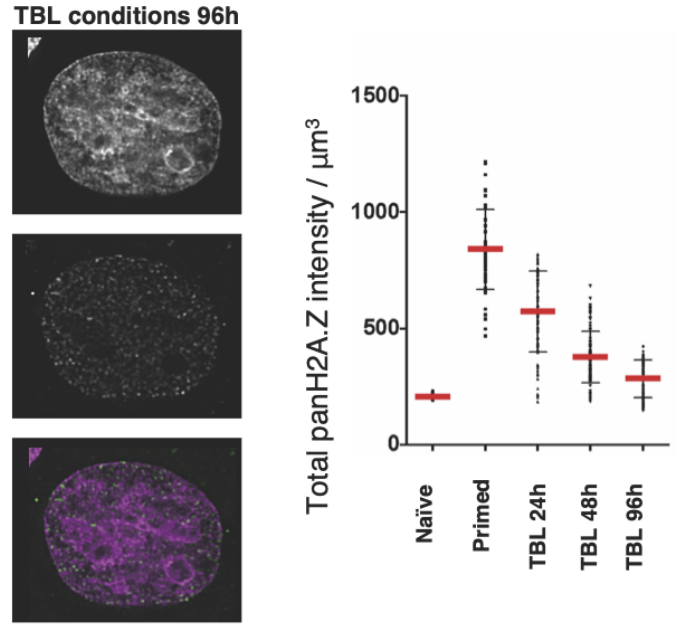

Supplemental Fig. 3. Immunofluorescence showing distribution of unmodified (pan-)H2A.Z. A, a timecourse of differentiation showing pan-H2AZ (middle row; green in merged image) and DAPI staining (top row, magenta in merged image). B, quantitation of H2A.Z intensity over the entire nucleus. C, peripheral shell analysis showing lack of enrichment at the nuclear periphery. 
bioRxiv preprint doi: https://doi.org/10.1101/2020.02.15.951103; this version posted February 16, 2020. The copyright holder for this preprint (which was not certified by peer review) is the author/funder, who has granted bioRxiv a license to display the preprint in perpetuity. It is made available under aCC-BY-NC-ND 4.0 International license.

\section{Figure S4}

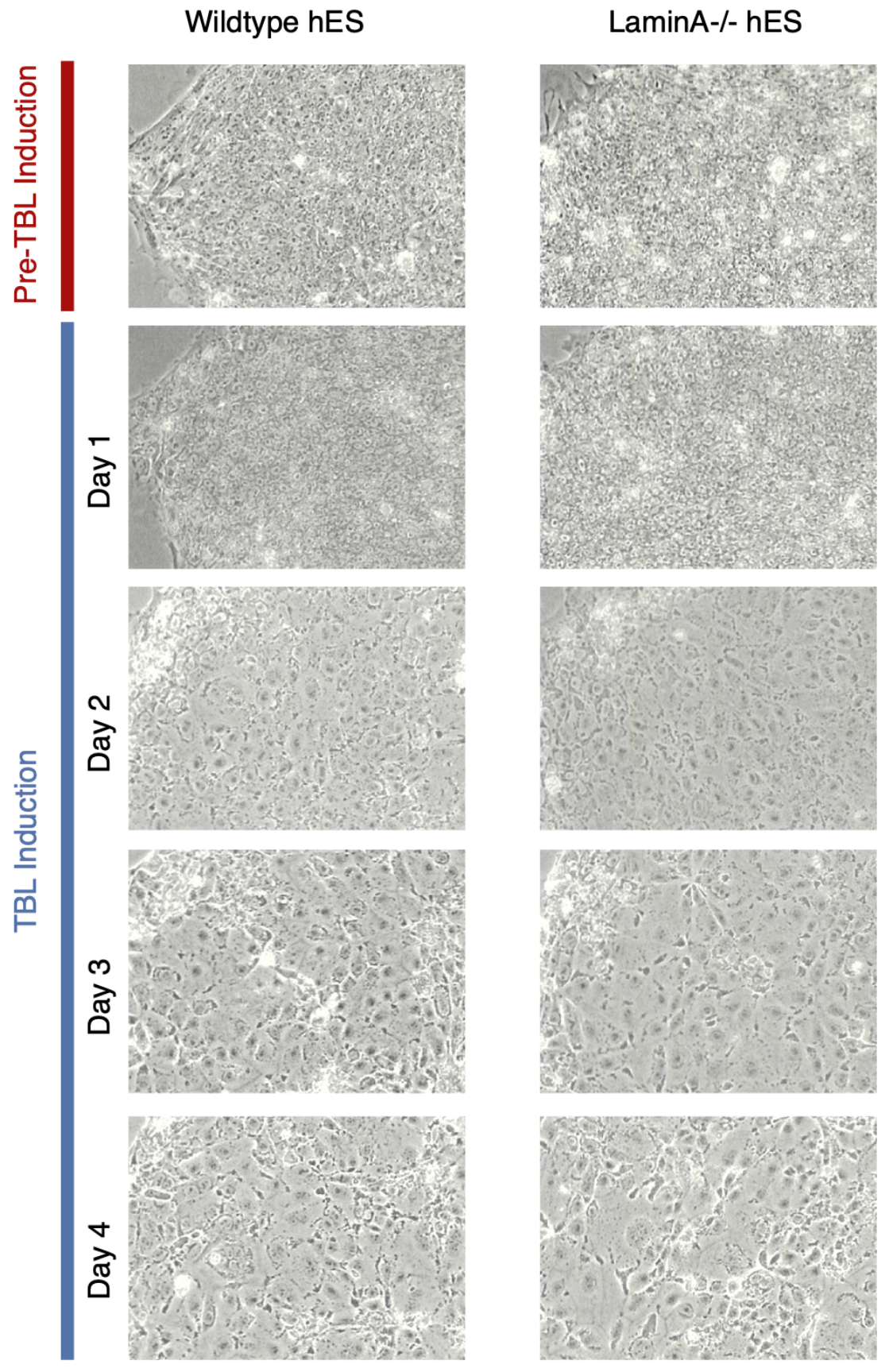

Supplemental Fig. 4. Bright-field fluorescence images of wild-type (left) and $\mathrm{LmnA}^{-/-}$cells (right) during the TBL induction timecourse at indicated timepoints (all images shown at the same magnification). 
bioRxiv preprint doi: https://doi.org/10.1101/2020.02.15.951103; this version posted February 16, 2020. The copyright holder for this preprint (which was not certified by peer review) is the author/funder, who has granted bioRxiv a license to display the preprint in perpetuity. It is made available under aCC-BY-NC-ND 4.0 International license.

Figure S5

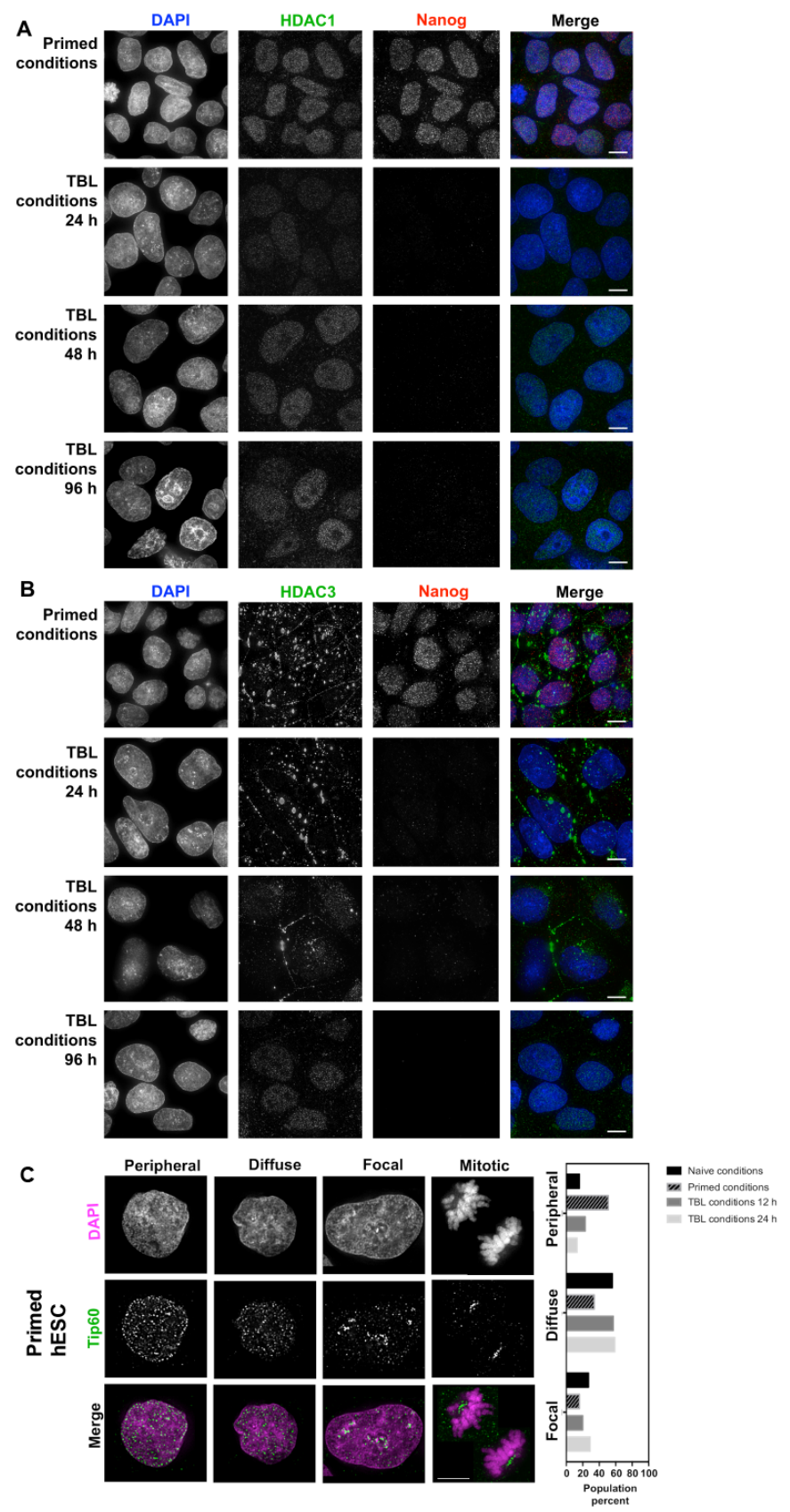

Supplemental Fig. 5. Immunofluorescence showing distribution of HDAC1 (A) and HDAC3 (B) over a differentiation timecourse. HDACs are labeled green in the merged image; Nanog immunofluorescence is labeled red in the merged image; DAPI counterstaining of DNA is shown in blue. Stages are indicated at left. Scale bars, $5 \mu \mathrm{m}$. C, immunofluorescence of Tip60 staining in primed hESC. Representative images are shown for each staining pattern observed. Right, prevalence of each staining type as a fraction of population at the indicated times. 